\title{
Surface characterisation \\ of 2D transition metal carbides (MXenes)
}

\author{
Ingemar Persson
}


Linköping Studies in Science and Technology Dissertation No. 1986

\title{
Surface characterization of 2D transition metal carbides (MXenes)
}

\author{
Ingemar Persson
}

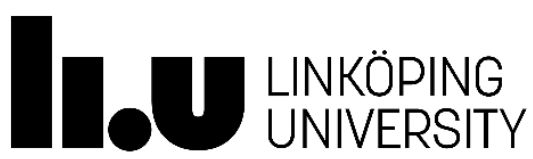

Thin Film Physics Division

Department of Physics, Chemistry and Biology (IFM)

Linköping University

SE-581 83 Linköping, Sweden

Linköping 2019 

Cover: Isolated $\left(\mathrm{Mo}_{2 / 3} \mathrm{Y}_{1 / 3}\right)_{2} \mathrm{CT}_{\mathrm{X}} \mathrm{MXene} \mathrm{sheet} \mathrm{imaged} \mathrm{in} \mathrm{plan} \mathrm{view.}$

(C) Ingemar Persson, 2019

Printed in Sweden by LiU-Tryck, Linköping 2019

ISSN 0345-7524

ISBN 978-91-7685-085-5 

"X: What is he working with again?
Y: I think he is looking very very carefully at very very small things..." 


\section{ABSTRACT}

Research on two-dimensional (2D) materials is a rapidly growing field owing to the wide range of new interesting properties found in $2 \mathrm{D}$ structures that are vastly different from their three-dimensional (3D) analogues. In addition, 2D materials embodies a significant surface area that facilitates a high degree of surface reactions per unit volume or mass, that is imperative in many applications such as catalysis, energy storage, energy conversion, filtration, and single molecule sensing. MXenes constitute a family of 2D materials consisting of transition metal carbides and/or nitrides, which are typically formed after selective etching of their 3D parent MAX phases. The latter, are a family of nanolaminated compounds that typically follow the formula $M_{n+1} A X_{n}(n=1-3)$, where $M$ is a transition metal, $\mathrm{A}$ is a group 13 or 14 element, and $\mathrm{X}$ is $\mathrm{C}$ and or $\mathrm{N}$. Selective etching by aqueous F- containing acids removes the A layer leaving $2 \mathrm{D} \mathrm{M}_{\mathrm{n}+1} \mathrm{X}_{\mathrm{n}}$ slabs instantly terminated by a mix of O-, OH- and F-groups. The first and most investigated MXene is $\mathrm{Ti}_{3} \mathrm{C}_{2} \mathrm{~T}_{\mathrm{X}}$, where $\mathrm{T}_{\mathrm{X}}$ stands for surface termination, which has shown record properties in a range of applications (eg. electrode in Li-batteries, supercapacitors, sieving membrane, electromagnetic interference shielding, and carbon capture). Adding to that, over 30 different MXenes have been discovered 
since 2011, exhibiting alternative or superior properties. Most importantly, elegant routes for property design in the MXene family has been demonstrated, by means of either varying the chemistry in the $\mathrm{M}_{\mathrm{n}+1} \mathrm{X}_{\mathrm{n}}$ compound, by alloying two $\mathrm{M}$ elements, or by changing the structure of the MXene by introducing vacancies.

The present work has a led to an additional route for post synthesis property tuning in MXenes by manipulation of surface termination elements. This enables a unique toolbox for property tuning which is not available to other 2D materials and is highly beneficial for applications that is dependent on surface reactions. Furthermore, chemical and structural characterization of terminations on single sheets is essential to rule out the influence of intercalants or contamination that is typically present in multilayer MXene samples or thin films. For that purpose, a method for preparing isolated contamination free single sheets of MXene samples for transmission electron microscopy (TEM) characterization was established. In order to determine vacancy and termination sites, atomically resolved scanning (S)TEM imaging and image simulations was carried out. Two main processes were employed to substitute the termination elements.

1) An initial thermal treatment in vacuum facilitates $F$ desorption and it was shown that O-terminations rearranges on the evacuated sites. $\mathrm{H}_{2}$ gas exposure in a controlled environment demonstrated a removal of the remaining O-terminations. As a result, termination-free MXene is possible to realize under vacuum conditions.

2) $\mathrm{CO}_{2}$ was introduced as a first non-inherent termination on MXene by in situ $\mathrm{CO}_{2}$ gas exposure at low temperatures. That was a first 
demonstration of $\mathrm{Ti}_{3} \mathrm{C}_{2} \mathrm{~T}_{\mathrm{X}}$ as promising material for carbon capture. Additionally, O-saturated surfaces were demonstrated after introduction of $\mathrm{O}_{2}$ gas on the F-depleted $\mathrm{Ti}_{3} \mathrm{C}_{2} \mathrm{~T}_{\mathrm{X}}$ MXene, which is highly relevant for hydrogen evolution reactions where fully O-terminated $\mathrm{Ti}_{3} \mathrm{C}_{2} \mathrm{~T}_{\mathrm{X}}$ are predicted to improve efficiency.

A Lewis acid melt synthesis method was used to realize the first MXene exclusively terminated with $\mathrm{Cl}$. Moreover, this was the first report of a MXene directly synthesised with terminations other than $\mathrm{O}$, $\mathrm{OH}$, and $\mathrm{F}$.

Furthermore, we have expanded the space of property tuning by introduction of chemical ordering, by selective etching of $\mathrm{Y}$ in an alloyed $\left(\mathrm{Mo}_{2 / 3} \mathrm{Y}_{1 / 3}\right)_{2} \mathrm{CT}_{\mathrm{X}}$ MXene. This either produced chemical ordering with one M (Mo) element and vacancies, or ordering between two M (Mo and Y) elements. This was further reported to significantly increase volumetric capacitance because of the increased number of active sites around vacancies, leading to an increasing charge density. As a final note, the stability of $\mathrm{Nb}_{2} \mathrm{CTX}$ MXene under ambient conditions was investigated. It was found that the surface $\mathrm{Nb}$ adatoms, present after etching, got oxidized over time which resulted in local clustering and effectively degraded the MXene.

This work has demonstrated reproducible surface characterization methods for determining termination elements and sites in 2D MXenes, that is ultimately governing MXene properties. Most importantly, we report on a new approach for MXene property tuning as well as contributing to several existing property tuning approaches. 


\section{POPULÄRVETENSKAPLIG SAMMANFATTNING}

Tvådimensionella material är en ny klass av material som består till största del ytor, vilket innebär att de besitter inga volymegenskaper till skillnad från 3D-material (de allra flesta materialen är 3D). Faktumet att 2D-egenskaperna är så olika volymegenskaperna för samma material, har drivit forskning de senaste 15 åren till att hitta och karaktärisera nya 2D material. På grund av att dessa material består av ytor, medför det att de är mycket lovande inom tillämpningar som är beroende av stor yta per viktenhet eller volymenhet (t.ex. katalys, energilagring, energikonvertering, filtrering eller sensorer).

MXener är en familj av material som tillhör klassen 2D-material bestående av övergångsmetall-karbider och eller -nitrider, typiskt realiserade genom kemisk etsning av deras 3D-motsvarigheter, MAXfaser. Den senare är en grupp material som är laminerade på atomnivå (liknande grafit) och har en generell form på hur lagren är arrangerade, $\mathrm{M}_{\mathrm{n}+1} \mathrm{AX}_{\mathrm{n}}(n=1-3)$. M är ett övergångsmetallager separerat av et Xlager, där $X$ är antingen $C$ eller N. Dessa MX-strukturer är dessutom separerade av ett A lager bestående av ett grupp 13 eller 14 element t.ex. Al eller Si. Kemisk selektiv etsning med hjälp av vattenbaserade, Finnehållande syror avlägsnar A-lagret och kvar står MX-strukturerna med ytor täckta av en kombination av $\mathrm{O}, \mathrm{OH}$ och $\mathrm{F}$, s.k. termineringar. 
Det först upptäcka, och även det mest undersökta MXenet är $\mathrm{Ti}_{3} \mathrm{C}_{2} \mathrm{~T}_{\mathrm{X}}$, där Tx står för yt-terminering, har påvisats rekordhöga egenskaper för en mängd tillämningar (bl.a. elektroder i Li-batterier, superkondensatorer, avskiljningsfilter, elektromagnetiska interferenssköldar och kolinfångning). Utöver detta har redan 30 stycken olika MXene upptäckts besittande alternativa eller enastående egenskaper. Nämnvärt är att en elegant process har påvisats för att styra egenskaper på det MXenematerial man vill framställa för en viss tillämning. Nämligen antingen att variera kemin i MX-strukturen (alltså välja övergångmetaller och eller C, N-innehåll), eller så att legera två olika övergångsmetaller, eller att ändra strukturen via introduktion av vakanser (tomma atompositioner).

Den här avhandlingen har resulterat i ytterligare en metod för att styra egenskaper i MXene via substitution av yt-termineringsämnen. Detta tillgängliggör verktyg för att styra egenskaper $i$ en utsträckning inga andra 2D-material besitter, och detta är mycket fördelaktigt i alla tillämpningar som är beroende av yt-reaktioner. Utöver detta är det nödvändigt med strukturell och kemisk karaktärisering på atomnivå över enskilda flak av 2D-material för att kunna utesluta all påverkan från inskjutna ämnen mellan flera 2D-lager eller kontaminering. Av den anledningen har en metod för att preparera fristående kontaminationsfria enskilda flak av MXener tagits fram för undersökning i ett transmissionselektronmikroskop (TEM). Föra att bestämma precisa platser på vakanser samt termineringar genomfördes atomupplösta avbildningar i ett svep-TEM (STEM) i kombination med STEMavbildningssimuleringar.

Två processer har nyttjats för att substituera termineringsämnen. En initial termisk behandling under vakuum påtvingar F-desorption följt av en omfördelning av resterande $\mathrm{O}$ på minimaenergi-platser som frigjorts från F. Efter en värmebehandling infördes vätgas i en kontrollerad miljö vilket resulterade $\mathrm{i}$ avlägsnandet av resterande $\mathrm{O}$ på ytan. Följaktligen är en termineringsfri yta på MXener realiserbar under vacuum. Efter detta steg fördes koldioxidgas in för att reagera med MXenet och $\mathrm{CO}_{2}$ demonstrerades som en ny termineringsgrupp på MXene. Detta var första gången en helt annan terminering än $\mathrm{O}, \mathrm{OH}$ eller $\mathrm{F}$ (som uppstår $\mathrm{i}$ 
syntesen) introducerats. Ytterst intressant var själva tillämpningen av en sådan process, nämligen kolavskiljning. Förutom $\mathrm{CO}_{2}$ exponerades även den F-fria ytan för syrgas vilket resulterade i en syremättad yta som i sig har påvisats teoretiskt vara mycket relevant i väteutvecklingstillämningar (engelsk förkortning HER).

Klor-terminerade MXener framställdes för första gången genom en ny syntesmetod baserad på Lewis acids. Vi har även utökat möjligheter för att styra egenskaper via elementvis uppordning inom varje atomlager i MXener genom selektiv etsning Y i ett $\left(\mathrm{Mo}_{2 / 3} \mathrm{Y}_{1 / 3}\right)_{2} \mathrm{CT}_{\mathrm{X}} \mathrm{MXene}$. Detta resulterade $\mathrm{i}$ antingen en ordnad struktur där $\mathrm{Y}$ ersatts av vakanser eller en struktur där Mo och Y är kemiskt ordnade i sina atomlager tillsammans med slumpmässiga vakanser. Detta ledde till en signifikant ökning av volymetrisk kapacitans på grund av den ökade mängden aktiva platser kring vakanser. Slutgiltligen undersöktes stabiliteten av $\mathrm{Nb}_{2} \mathrm{CT}_{\mathrm{X}} \mathrm{MXene}$ under normala förhållanden. Där fann vi att yt-adatomer av $\mathrm{Nb}$ som uppstår i syntesen, blev oxiderade för att sammanfogas till större kluster och till slut degradera MXenet.

Det här arbetet har möjliggjort ett nytt tillvägagångssätt för att styra 2D MXeners egenskaper samt även bidragit till att expandera existerande metoder. Utöver detta har en reproducerbar process tagits fram för att karaktärisera vakanser och termineringar på atomnivå för enskilda 2Dflak. 


\section{PREFACE}

This thesis is the result of research performed at the Thin film Physics Division at the Department of Physics, Chemistry and Biology (IFM), Linköping University, Sweden, between January 2015 and June 2019.

The research has focused on surface characterization of 2D MXenes by employing aberration corrected TEM techniques including quantitative HAADF STEM and HRTEM for atomic resolution imaging, EELS to quantify elemental composition of surfaces, ED to determine crystal structures as well as in situ TEM techniques to modify the surface chemistry of MXenes. Moreover, STEM simulations were carried out to aid experimental interpretation.

TEM experiments were performed at the Electron Microscopy Laboratory at Linköping University and at the Centre for Electron Nanoscopy at the Technological University of Denmark (DTU CEN).

This work has been supported by the Swedish Research Council for funding under grants no. 621-2012-4359, 622-2008-405, 2013-5580, 2016-04412, 642-2013-8020, and the Knut and Alice Wallenberg's Foundation for support of the electron microscopy laboratory in Linköping, the Swedish Foundation for Strategic Research (SSF) through the Synergy Grant FUNCASE, and the Research Infrastructure Fellow program (RIF14-0074), the Swedish Government Strategic Research Area in Materials Science on Functional Materials at Linköping University (Faculty Grant SFO-Mat-LiU No 2009 00971). 


\section{ACKNOWLEDGEMENTS}

First and foremost, I want to thank Per, for organizing an amazing study visit at the Electron Microscopy Laboratory at Linköping University during my Master's studies. I would not be working with one of the best cameras in the world, and within a field that is so stimulating and rewarding, if it wasn't for him. Thank you for that.

I also want to thank him for all the support he has given me over the years, for teaching me TEM, and for allowing me to attend expensive state-of-the-art courses all over the world to improve my knowledge of TEM, and of course for always providing me with interesting topics to investigate.

Most of all I want to thank him for the patience he has shown throughout my project when I have, almost consistently, delayed in producing results.

I want to thank Justinas for spending many hours with me in the TEM going through all the specific modes of operations and always having time for answering questions when I needed, and for tea breaks. I want to thank all my supervisors Per, Justinas, Johanna, and Vanya for critically reviewing my work, helping me improve in analysis and article writing.

I want to thank Thomas for all the assistance with equipment and whatnot and for not getting too upset when I destroy his instruments. I also want to thank him for very practical lessons in safety during TEM repairs. Especially how not to do. Mostly I want to thank him for all the breaks and chats and interesting times on conferences. 
I want to thank all co-authors for making publications possible, especially big thanks to Joseph and Tao for providing samples.

Babak, Melike, you are amazing neighbours, thank you for making every day at work fun, and for always listening and offering your help.

Nerijus, Robin, Lida, Joseph, Laurent, Alexandra, Nils, Sebastian, Hengfang, Clio, and Alexis, thanks for all the fun times.

To the fika group! Keep it going, fika is important! I just wish more of you would join the 9 am fika. :-

I want to thank my colleagues in Thin Film Physics for all the good times and fruitful discussions at lunch, Friday fika, summer meetings, and Christmas meetings.

Thank you to agora for the support and thank you to all agora members for memorable times at conferences and meetings.

I want to thank Jakob and Thomas at DTU, Copenhagen for their help and expertise with the ETEM.

I want to thank my fellow microscopists for making conferences and workshops unforgettable. Elisa, I will never forget Franky’s pizza (-)

I want to thank my family for the constant support and encouragement.

Thank you, Winston and Isa, I would be lost without you.

Thank you, Frida, for all the support.

Erika, thank you for everything. 


\section{PAPERS INCLUDED IN THE THESIS}

\section{Paper 1.}

On the organization and thermal behavior of functional groups on $\mathrm{Ti}_{3} \mathrm{C}_{2}$ MXene surfaces in vacuum

Ingemar Persson ${ }^{1}$, Lars-Åke Näslund ${ }^{1}$, Joseph Halim ${ }^{1,2}$, Michel W Barsoum $^{1,2}$, Vanya Darakchieva ${ }^{3}$, Justinas Palisaitis ${ }^{1}$, Johanna Rosen ${ }^{1}$ and Per O. A.. Persson ${ }^{1}$

2D Mater. 5 (2018) 015002

1 Thin Film Physics Division, Department of Physics Chemistry and Biology, Linköping University, SE-581 83 Linköping, Sweden

${ }^{2}$ Department of Materials Science and Engineering, Drexel University, Philadelphia, PA 19104, United States of America

${ }^{3}$ Semiconductor Materials Division Department of Physics Chemistry and Biology, Linköping University, SE-581 83 Linköping, Sweden.

I was involved in designing the experiments. I performed STEM experiments and analysis, performed STEM simulations and analysis. I wrote part of the draft and contributed to the final version of the manuscript. 


\section{Paper 2.}

\section{D Transition Metal Carbides (MXenes) for Carbon Capture}

Ingemar Persson ${ }^{1}$, Joseph Halim ${ }^{1}$, Hans Lind ${ }^{1}$, Thomas W. Hansen ${ }^{2}$, Jakob B. Wagner ${ }^{2}$, Lars-Åke Näslund ${ }^{1}$, Vanya Darakchieva ${ }^{3}$, Justinas Palisaitis ${ }^{1}$, Johanna Rosen ${ }^{1}$, and Per O. Å. Persson ${ }^{1}$

Adv. Mater. 2019, 31, 1805472

${ }^{1}$ Thin Film Physics Division, Department of Physics, Chemistry and Biology (IFM), Linköping University, SE-581 83 Linköping, Sweden

${ }^{2}$ Center for Electron Nanoscopy, Technical University of Denmark (DTU), Danchip/CEN, DK-2800 Kgs. Lyngby, Denmark

${ }^{3}$ Terahertz Materials Analysis Center (THeMAC), Department of Physics, Chemistry and Biology (IFM), Linköping University, SE-581 83 Linköping, Sweden.

I took part in the design of the experiments. I carried out TEM experiments and analysis, performed in situ gas exposure experiments and residual gas analysis. I wrote the draft and contributed to the final version of the manuscript.

\section{Paper 3.}

\section{O-saturation on defluorinated $2 \mathrm{D} \mathrm{Ti}_{3} \mathrm{C}_{2} \mathrm{~T}_{\mathbf{X}}$ MXene surfaces}

Ingemar Persson, Joseph Halim, Justinas Palisaitis, Johanna Rosen and Per O. Å. Persson

\section{Manuscript in final preparation}

Department of Physics Chemistry and Biology, Thin Film Physics Division, Linköping University, SE-581 83 Linköping, Sweden.

I contributed to the design of the experiments. I conducted TEM experiments and analysis, as well as in situ gas exposure experiments and analysis. I wrote the draft and contributed to the final version of the manuscript. 


\section{Paper 4.}

Tin+1Cn MXene with fully saturated and thermally stable Cl terminations

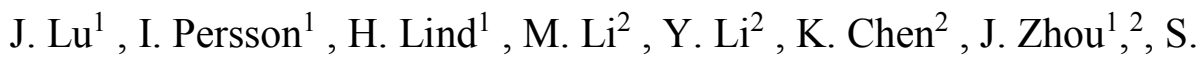
$\mathrm{Du}^{2}$, Z. Chai ${ }^{2}$, Z. Huang ${ }^{2}$, L. Hultman ${ }^{1}$, J. Rosen ${ }^{1}$, P. Eklund ${ }^{1}$, Q. Huang $^{2}$, and P.O.A. Persson ${ }^{1}$

Submitted

1 Thin Film Physics Division, Department of Physics, Chemistry and Biology (IFM), Linköping University, SE-581 83 Linköping, Sweden 2 Engineering Laboratory of Advanced Energy Materials (FiNE Lab.), Ningbo Institute of Industrial Technology, Chinese Academy of Sciences, Ningbo, Zhejiang, 315201, China

I performed STEM simulations and analysis. I wrote part of the draft and contributed to the final version of the manuscript.

\section{Paper 5.}

Tailoring Structure, Composition, and Energy Storage Properties of MXenes from Selective Etching of In-Plane, Chemically Ordered MAX Phases

Ingemar Persson ${ }^{1}$, Ahmed el Ghazaly ${ }^{1}$, Quanzheng Tao ${ }^{1}$, Joseph Halim ${ }^{1}$, Sankalp Kota ${ }^{2}$, Vanya Darakchieva ${ }^{3}$, Justinas Palisaitis ${ }^{1}$, Michel W. Barsoum $^{2}$, Johanna Rosen ${ }^{1}$, and Per O. Å. Persson ${ }^{1}$

Small $2018,14,1703676$

${ }^{1}$ Thin Film Physics Division, Department of Physics, Chemistry and Biology (IFM), Linköping University, SE-581 83 Linköping, Sweden

${ }^{2}$ Department of Materials Science and Engineering, Drexel University, Philadelphia, PA 19104, USA 
3 Terahertz Materials Analysis Center and Center for III-Nitride Technology C3NiT-Janzén, Department of Physics Chemistry and Biology (IFM), Linköping University, SE-581 83 Linköping, Sweden.

I took part in designing the experiments. I performed STEM experiments and analysis. I wrote part of the draft and contributed to the final version of the manuscript.

\section{Paper 6.}

On the Structural Stability of MXene and the Role of Transition Metal Adatoms

Justinas Palisaitis, Ingemar Persson, Joseph Halim, Johanna Rosen and Per O. Å. Persson

Nanoscale, 2018, 10, 10850

Thin Film Physics Division, Department of Physics Chemistry and Biology, Linköping University, SE-581 83 Linköping, Sweden.

I was involved in designing the experiments. I performed STEM simulations and analysis. I wrote part of the draft and contributed to the final version of the manuscript. 


\section{RELATED PAPERS}

Electronic and optical characterization of $2 \mathrm{D} \mathrm{Ti}_{2} \mathrm{C}$ and $\mathrm{Nb}_{2} \mathrm{C}$ (MXene) thin films Joseph Halim, Ingemar Persson, Eun Ju Moon, Philipp Kühne, Vanya Darakchieva, Per O. A. Persson, Per Eklund, Johanna Rosen and Michel W. Barsoum J. Phys.: Condens. Matter, 2019, 31, 165301

Sodium hydroxide and vacuum annealing modifications of the surface terminations of a $\mathrm{Ti}_{3} \mathrm{C}_{2}$ (MXene) epitaxial thin film

Joseph Halim, Ingemar Persson, Per Eklund, Per O. A. Persson and Johanna Rosen

RSC Adv., 2018, 8, 36785

Room-temperature mobility above $2200 \mathrm{~cm}^{2} / \mathrm{V}$ s of two-dimensional electron gas in a sharp-interface $\mathrm{AlGaN} / \mathrm{GaN}$ heterostructure

Jr-Tai Chen, Ingemar Persson, Daniel Nilsson, Chih-Wei Hsu, Justinas Palisaitis, Urban Forsberg, Per O. A. Persson, and Erik Janzén

Appl. Phys. Lett. 106, 251601 (2015)

Structural properties and dielectric function of graphene grown by hightemperature sublimation on $4 \mathrm{H}-\mathrm{SiC}(000-1)$

C. Bouhafs, V. Darakchieva, I. L. Persson, A. Tiberj, P. O. A. Persson, M. Paillet, A.-A. Zahab, P. Landois, S. Juillaguet, S. Schöche, M. Schubert, and R. Yakimova J. Appl. Phys., 2016, 117, 085701 


\section{CONTENTS}

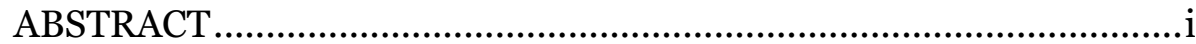

POPULÄRVETENSKAPLIG SAMMANFATTNING ............................ iv

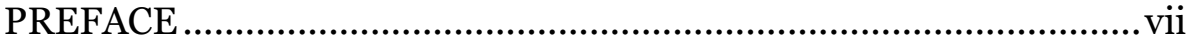

ACKNOWLEDGEMENTS ............................................................... viii

PAPERS INCLUDED IN THE THESIS...............................................

RELATED PAPERS ........................................................................ .

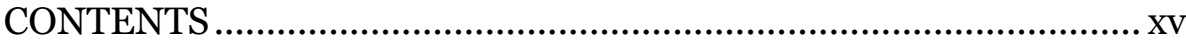

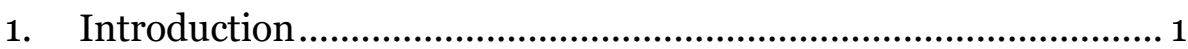

1.1. General introduction................................................................ 1

1.2. Two-dimensional materials, advantages and challenges ...............2

1.3. MXenes and their properties .............................................................. 3

1.4. Research objectives..........................................................................4

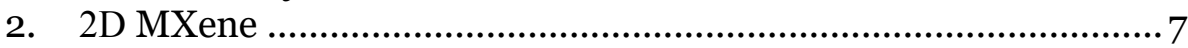

2.1. The 2D flatland ............................................................................ 7

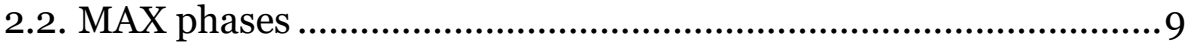

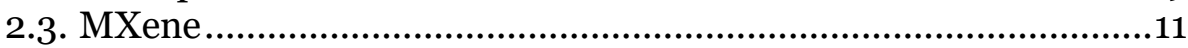

2.3.1. MAX powder synthesis and etching ........................................... 12

2.3.2. MAX thin film synthesis and etching ......................................... 13

2.3.3. MXene intercalation and delamination ......................................... 14

2.4. MXene properties and applications........................................... 16

2.4.1. Energy storage............................................................................ 16

2.4.2. Electronic properties ................................................................. 17

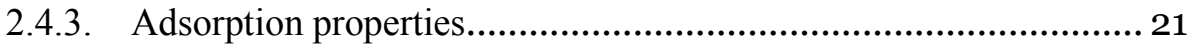

2.5. Modification of surface chemistry …….......................................22

3. Characterization............................................................................25

3.1. Transmission electron microscopy …........................................26

3.1.1. Principles of TEM............................................................28

3.1.2. Electron scattering ............................................................. 31

3.1.3. Image contrast .............................................................. 33

3.1.4. Aberrations and correctors ……............................................ 35

3.2. High angle annular dark field STEM ...........................................39 


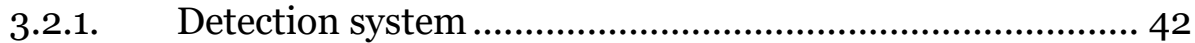

3.3. STEM image simulations ……..................................................... 43

3.4. Quantitative HAADF STEM ........................................................ 44

3.5. Electron energy-loss spectroscopy .............................................45

3.6. In situ TEM ............................................................................... 48

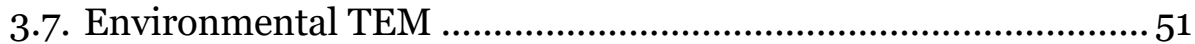

3.8. Electron diffraction ..................................................................52

3.9. X-ray photoelectron spectroscopy …….......................................52

3.10. Residual gas analysis .............................................................55

4. Contributions to the field ...........................................................54 


\section{Introduction}

\subsection{General introduction}

In the world of the very small, less is more. That is true for materials confined in one dimension, commonly referred to as $2 \mathrm{D}$, i.e. with a thickness of a few atoms. The most general benefits of reducing dimensions are the low amount of material and space required for a 2D component in contrast to a 3D device, and the incredibly high surface area per weight unit. ${ }^{1}$ The first 2D material realized (graphene) exhibits excellent electronic properties and is only 1 atomic layer thick, ${ }^{2}$ which is about 0.3 nanometer $(\mathrm{nm})$. Electronics for integrated circuits in computers, mobile phones, and other portable devices, ${ }^{3,4}$ is one of the fields that is now advancing on the very small (nano) scale. Increased processing power leads to a higher power consumption and heat generation, as more components are packed in smaller volumes and therefore requires more cooling. To reduce power consumption and heat generation per unit area, the trend is to reduce device sizes. 5 Silicon is the industrially used material in integrated circuits, however challenges emerge when device dimensions are now reaching below $5 \mathrm{~nm}$. 2D materials are promising candidates for replacing silicon in future electronics. Energy storage is another field that is currently profiting from nano-sized materials, allowing for more energy stored per weight unit. ${ }^{6,7}$ Catalysis requires active surface sites to reduce or convert molecules into desired products and it is therefore advantageous to retain a large surface area. ${ }^{8,9}$ Another important field that benefits from high surface to volume ratio is adsorption for filtering ${ }^{10}$ or sensor ${ }^{11}$ applications. However, to 
understand properties of 2D materials and exploit them in the design of new devices require characterization of surfaces down to the atomic level.

\subsection{Two-dimensional materials, advantages and challenges}

2D materials exhibit properties very different from their compound counterparts. 12 These properties arise from surface effects that are dominant for 2D materials, in contrast to volume effects for compounds, aka bulk materials. ${ }^{12}$ Consequently, the last decade has seen extensive research in 2D materials. Typically, 2D materials are synthesized by exfoliation of layered bulk materials, graphene being the leading example obtained by exfoliation of graphite, ${ }^{2}$ resulting in the 2010 Nobel prize in physics. Exfoliation can be performed mechanically, e.g. by the scotch tape method, ${ }^{2}$ or chemically by liquid exfoliation. ${ }^{13,14}$ In general, mechanical exfoliation can be applied on materials where adjacent layers are bonded by weak van der Waals forces, like graphite. It is a method that offers high quality but remains a challenge in terms of mass production. On the contrary, liquid exfoliation exploits chemical reactions and can therefore be applied to layers that more strongly bonded. Furthermore, it has great potential for large scale production but is more challenging with respect to high quality. In addition, 2D materials growth is feasible using e.g. chemical vapour deposition (CVD) or physical vapour deposition (PVD), however the challenge with these techniques is that a post growth transfer is required in order to make use of the $2 \mathrm{D}$ material for devices.

An important advantage of 2D materials is that isolated layers can be regarded as nanosized building blocks. They can be stacked forming heterostructures with a wide range of different properties, including 2D semiconductors. ${ }^{15,16}$ In addition, owing to the large surface area per unit volume, reactions on the surface can be utilized to manipulate and tune 
materials properties. Surfaces can be functionalized, meaning tuned by introducing terminations with different chemistries to promote or prevent certain reactions. ${ }^{17,18}$ Consequently, atomic level control of the surface during synthesis is crucial in order to avoid unintentional surface reactions and by extension, unintentional materials properties.

Altogether, there is a high demand for advanced 2D materials with a large surface area, suitable for mass production, that contain several different chemistries, and with the potential for tailoring surface terminations and vacancies opens up for a vast range of variables that can be tuned in order to obtain desired properties.

\subsection{MXenes and their properties}

MXenes comprises a large family of 2D materials consisting of transition metal carbides and/or nitrides, formed by chemical etching of its parent compound MAX phase. ${ }^{19}$ The latter constitute a set of atomically laminated compounds described by the formula $\mathrm{M}_{n+1} A X_{n}(n=1-3)$. Here, $\mathrm{M}$ is a transition metal layer bonded to an $\mathrm{X}$ layer (either $\mathrm{C}$ and or $\mathrm{N}$ ) and $A$ is a layer of a group 13 or 14 element separating the slabs of $M_{n+1} X_{n}$. Selective etching with for example hydrofluoric acid removes the A layer but leaves the $\mathrm{M}_{\mathrm{n}+1} \mathrm{X}_{\mathrm{n}}$ MXene sheets intact (-ene coming from graphene highlighting their two-dimensionality). ${ }^{20}$ As a consequence of the etching, previous reports suggests that the surfaces becomes inherently terminated by a mix of O-, OH- and F-groups. ${ }^{20,21,22}$ To highlight the surface terminating groups. The MXene formula becomes $M_{n+1} X_{n} T_{X}$, where $\mathrm{T}_{\mathrm{X}}$ denotes terminations.

$\mathrm{Ti}_{3} \mathrm{C}_{2} \mathrm{~T}_{\mathrm{X}}$ was the first MXene to be discovered and has since then be investigate as potential candidate for electrode material in Li-batteries, ${ }^{23}$ supercapacitors, 7 molecular sieving membranes, 24 electromagnetic interference shielding, ${ }^{25}$ and carbon capture ${ }^{26,27}$ ). To date, more than 30 MXenes have been experimentally confirmed with many more predicted. ${ }^{28}$ Most importantly, it is possible to design MXene properties by varying MXene structure, composition or surface terminations. This is a unique toolbox for property design not available to any other 2D material, 
rendering MXenes promising for many more applications. Finally, the potential scalability of MXene synthesis compared to other 2D materials show great promise for mass production.

\subsection{Research objectives}

The purpose of this work was to investigate a new approach to design electronic, energy storage, catalytic, and adsorption properties of MXenes by varying the chemistry of the atoms bonded to the MXene surface, i.e. by, introducing new terminations, and/or vacancies, and/or by alloying two $\mathrm{M}$ elements. On that account, in situ transmission electron microscopy (TEM) techniques were employed to provide direct evidence on atomic structure, composition and chemistry of 2D MXenes with high spatial and energy precision.

(Paper 1) Inherent surface terminations are derived from the etching agents used in the synthesis, previous results suggest a mix of $\mathrm{O}, \mathrm{OH}, \mathrm{F}$ 19 that determines materials properties such as electronic properties, charge capacity, and adsorption efficiency. In paper 1 the main objective was to explore the possibilities of clearing the $\mathrm{Ti}_{3} \mathrm{C}_{2} \mathrm{~T}_{\mathrm{X}}$ MXene surfaces of inherent terminations by in situ thermal treatment in vacuum. Partial removal of inherent terminations was achieved as $\mathrm{F}$ was desorbed by vacuum heat treatment. In addition, a method for preparation of single MXene sheets, free from contaminants and/or intercalants was established in order to ensure that characterization was performed on the MXene without external influence.

(Paper 2) Following the knowledge established in paper 1, the next step was to remove the remaining inherent O-terminations by in situ gaseous exposure inside an environmental TEM (ETEM). In addition, as both steps were proven successful the natural follow-up was to, for the first time, terminate MXene surfaces by a non-inherent termination type. $\mathrm{CO}_{2}$ adsorption on $\mathrm{Ti}_{3} \mathrm{C}_{2}$ MXene was predicted with an efficiency 
comparable to industrially relevant materials. ${ }^{26}$ The final aim of paper 2 was therefore to experimentally investigate $\mathrm{Ti}_{3} \mathrm{C}_{2}$ MXene for carbon capture applications.

(Paper 3) Exclusively terminating MXenes with oxygen (e.g. $\mathrm{Ti}_{3} \mathrm{C}_{2} \mathrm{O}_{2}$ ) was predicted highly promising for ion intercalation battery, 29,30 supercapacitors 31,32 as well as hydrogen evolution reaction (HER) 33,34 applications. For that reason, the ambition of paper 3 was to introduce $\mathrm{O}$-terminations by in situ $\mathrm{O}_{2}$ exposure after thermal treatment in vacuum using ETEM.

(Paper 4) Fluorine-free MXene synthesis is preferred for applications, such as biocompatible MXene quantum dots for cancer therapy, ${ }^{35}$ and supercapacitors, ${ }^{36}$ where F-terminations are found to reduce volumetric capacity compared to O- and OH-terminations. On that account, in paper 4 the structure and thermodynamic stability for fully Cl-terminated MXene was investigated. MXenes were synthesized by Lewis acid melt method $\left(\mathrm{ZnCl}_{2}\right.$ and either $\mathrm{Ti}_{3} \mathrm{AlC}_{2}$ or $\left.\mathrm{Ti}_{2} \mathrm{AlC}\right)$.

(Paper 5) In-plane ordered MAX phases (i-MAX) are formed by alloying two different M-elements in the M-planes. ${ }^{37}$ Chemical etching of an i-MAX, $\left(\mathrm{Mo}_{2 / 3} \mathrm{Sc}_{1 / 3}\right)_{2} \mathrm{AlC}$, was previously shown to result in $\mathrm{Sc}$ and $\mathrm{Al}$ removal and the formation of vacancy ordered MXene with a higher volumetric capacitance then conventional MXene. ${ }^{37}$ The focus of paper 5 was therefore to investigate a new etching protocol for $\left(\mathrm{Mo}_{2 / 3} \mathrm{Y}_{1 / 3}\right)_{2} \mathrm{AlC}$ i-MAX and the possibility for tuning volumetric capacitance.

(Paper 6) The stability of MXenes in oxygen containing environments is known to degrade with time. ${ }^{38,39}$ In paper 6 the oxidation process of $\mathrm{Nb}_{2} \mathrm{CT}_{\mathrm{X}}$ was investigated, a promising material for Li-ion batteries, ${ }^{40}$ and photothermal cancer therapy. ${ }^{41}$ STEM investigations on atomic scale was employed to follow the structural evolution of $\mathrm{Nb}_{2} \mathrm{CT}_{\mathrm{X}}$ as a function of time in ambient conditions. 


\section{2D MXene}

This chapter initially describes the basic concepts surrounding 2D materials and their properties. Subsequently, a detailed account on MXene origin, structures, synthesis, properties and applications is given. The last paragraph discusses the strategies involved for tailored materials properties based on surface structure and chemistry.

\subsection{The $2 \mathrm{D}$ flatland}

The starting point for global research in 2D materials came with the 2010 Nobel prize in physics awarded to Geim and Novoselov for their efforts in isolating and characterizing a single atomic layer of $\mathrm{C}$ atoms, so called graphene. ${ }^{2}$ The fascinating properties that emerged only after thinning graphite down to a single atomic layer took the scientific community by surprise. Since then, graphene has been investigated for many applications, owing to the fact that graphene exhibits outstanding electric conduction and mechanical properties. The main examples include semiconductors ${ }^{42,43}$ energy related applications, ${ }^{44,45}$ and sensors. ${ }^{46,47}$ Beyond graphene, there are currently more than 70 experimentally verified 2D materials, ranging from; single atomic species (borophene, ${ }^{48}$ silicene, ${ }^{49}$ germanene, ${ }^{50}$ phosphorene ${ }^{51,52}$ and stanene ${ }^{53}$ ); to bi-atomic structures such as transition metal dichalcogenides (TMDs) including $\mathrm{MoS}_{2},{ }^{54} \mathrm{WS}_{2}{ }^{55}$ etc. and 2D nitrides (h-BN, ${ }^{56,57} \mathrm{CN},{ }^{58} \mathrm{GaN} 59$ etc.); to more complex structures such as transition metal oxides ${ }^{60,61}$ (TMOs) and MXenes. ${ }^{20}$ 

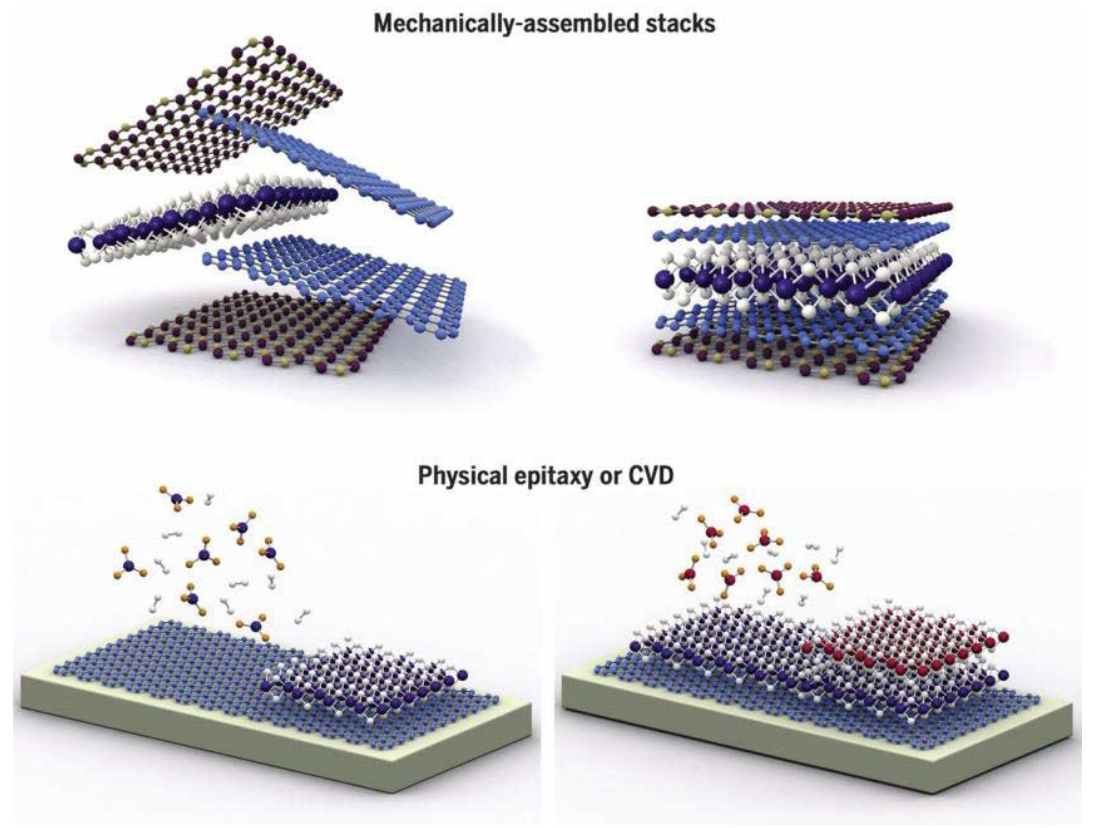

Figure 2.1: Examples of how 2D materials can be stacked, either by transfer techniques or by direct growth. ${ }^{62}$ Reused with permission from the American Association for the Advancement of Science (AAAS).

Recently, high throughput calculations have led to the predicted existence of over a 1000 new 2D materials based on stability after exfoliation of known 3D structures. ${ }^{63}$ Beyond that, the MXene family include more than 200 predicted structures. ${ }^{28}$ Altogether, the family $2 \mathrm{D}$ materials offer a wide range of new properties, opening up for nano-sized building blocks (see figure 2.1) which fashions them highly promising materials in many fields including metals, semiconductors, isolators, dielectrics, optoelectronics, battery technology, supercapacitors, magnetic materials, and nanopore materials. However, the simple chemistry that forms many $2 \mathrm{D}$ materials also becomes a drawback in terms of tunability of materials properties. For instance, graphene and h$\mathrm{BN}$ typically forms weak van der Waals bonds with adsorbed species, limiting functionalization. MXene is the material of focus in this thesis because of the highly versatile chemistries they offer, which opens up for tuning of many properties. However, to understand the structure and 
properties of 2D MXenes, one must first have some understanding of the 3D layered compound they are derived from, namely MAX phases.

\subsection{MAX phases}

The notation $M_{n+1} A X_{n}$, is used to describe the composition as well as the layered structure of the MAX phases. Each layer is flat and atomically thick and consist of a periodically repeated number of ' $M$ ' layers $(n+1)$ separated by ' $X$ ' layers ( $n$ ), where $n=1-3$. ' $M$ ' being early transition metals and ' $\mathrm{X}$ ' is carbon, nitrogen or a combination of the two. ${ }^{19}$ Figure 2.2 presents the laminar structure of the $\mathrm{Ti}_{2} \mathrm{AlC}$ and $\mathrm{Ti}_{3} \mathrm{AlC}_{2}$ MAX phases. Currently, more than 150 different MAX phases have been realized, ${ }^{64}$ including; conventional MAX phase, solid solutions with two 'M' elements, ${ }^{65,66}$ and chemically ordered MAX phases with two ' $M$ ' elements ordered out-of-plane (o-MAX), ${ }^{67}$ or with two elements ordered in-plane (i-MAX). ${ }^{37}$ The latter class, includes a wide range of rare earth metals.

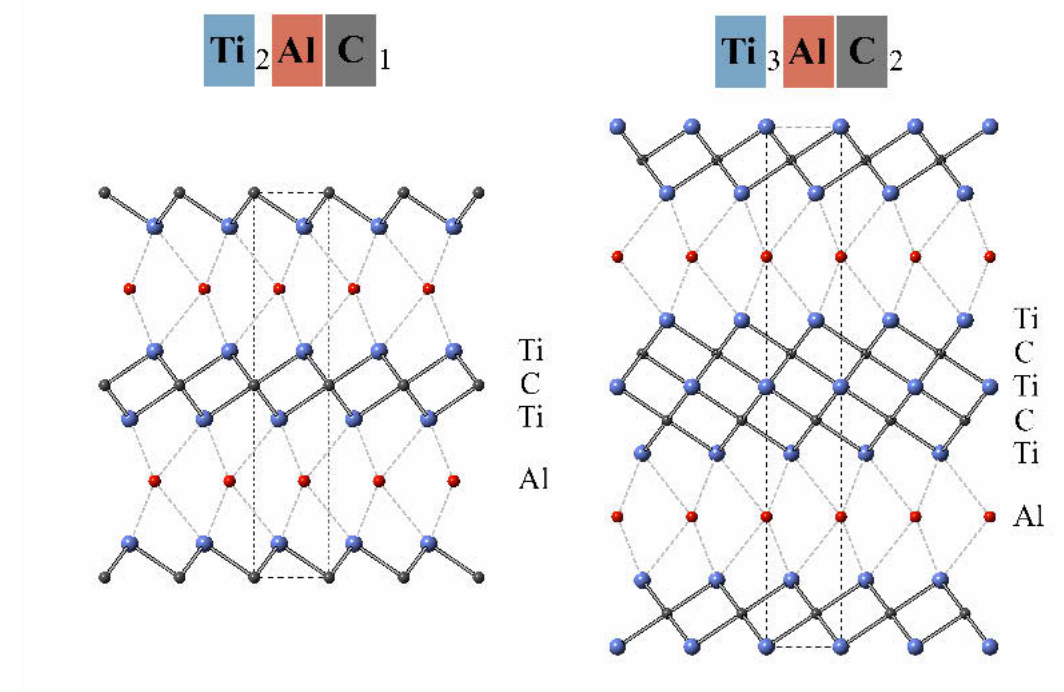

Figure 2.2: Atomic models of $\mathrm{Ti}_{2} \mathrm{AlC}$ and $\mathrm{Ti}_{3} \mathrm{AlC}_{2}$ MAX phases presenting their nanolaminate nature as well as the $\mathrm{M}-\mathrm{X}$ bonds (solid grey) and $\mathrm{M}-\mathrm{A}$ bonds (dashed grey). 


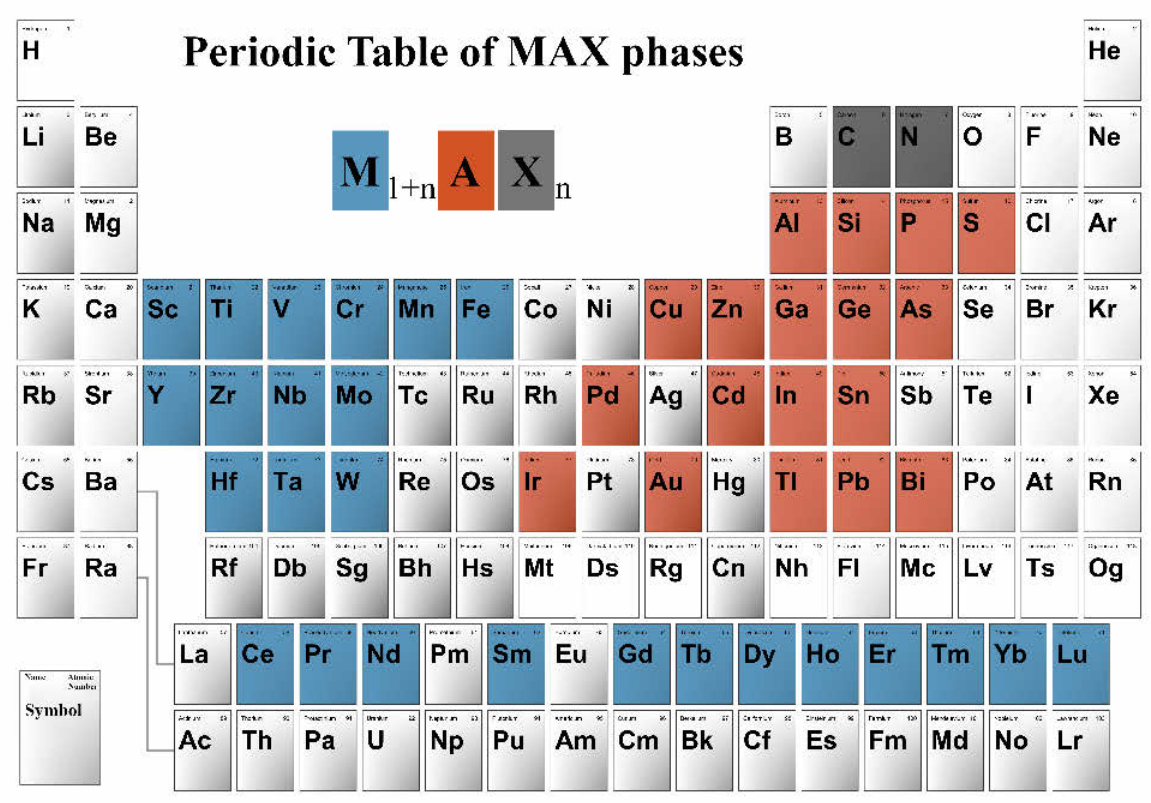

Figure 2.3: Periodic table showing the elemental combinations of known MAX phases, either in the conventional, solid solution, or chemically ordered form. ${ }^{60}$

Figure 2.3 illustrates the known elemental combinations resulting in a MAX phase. They are readily produced in large quantities because of the low-cost solid state pressure-less sintering method used to synthesize MAX powders. What renders MAX phases unique is that they possess a combination of metallic and ceramic properties stemming from the mix of strong M-X bonds forming sheets stabilized into a laminar structure by the weaker M-A bonds in between each sheet, see figure 3. The result is a chemically and thermally stable material at the same time as being elastically stiff but machinable. Furthermore, the compounds are electrically and thermally conductive as well as high-temperature shock and oxidation resistant. Lastly, the chemical diversity available to the MAX phase family opens up for many interesting applications. 


\subsection{MXene}

The first MXene to be discovered was $\mathrm{Ti}_{3} \mathrm{C}_{2}$, reported by Naguib et al. in 2011, where, by employing HF acid treatment of a $\mathrm{Ti}_{3} \mathrm{AlC}_{2} \mathrm{MAX}$ phase, they were able to remove the $\mathrm{Al}$ layers and isolate single $\mathrm{Ti}_{3} \mathrm{C}_{2}$ sheets. ${ }^{20}$ Figure 2.4 presents an atomic model of the structure of $\mathrm{Ti}_{3} \mathrm{C}_{2} \mathrm{~T}_{\mathrm{X}}$ in an a) [11̄̄0] cross-section and b) [0001] top-view orientation. The blue and red $\mathrm{Ti}$ layers are highlighted because they are especially important for materials properties as they form the bonds to the surface terminations $\left(\mathrm{T}_{\mathrm{X}}\right)$, which will be further discussed in the next section.

a)

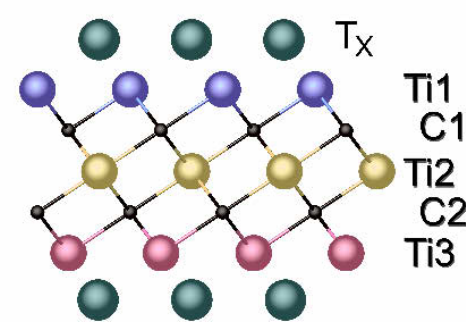

b)

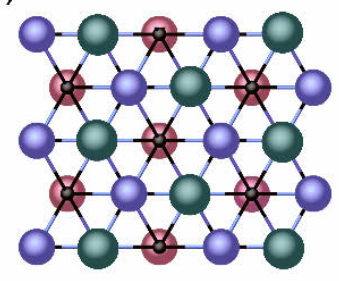

Figure 2.4: Atomic model of the $\mathrm{Ti}_{3} \mathrm{C}_{2} \mathrm{~T}_{\mathrm{X}}$ MXene structure in a) a [11 20 ] direction (side view) depicting the layered structure, and b) a [0001] direction (top view) illustrating the hexagonal lattice. Red and blue atoms are surface $\mathrm{Ti}$ atoms that typically form strong bonds with $\mathrm{O}, \mathrm{OH}$, and $\mathrm{F}$ surface terminations (green).

The most significant outcome of this finding is yet to be revealed, however, the fact that chemical etching methods were applicable to such a versatile family of materials as the MAX phases meant the birth of a new 2D family rich in compositional variations. Since then $\mathrm{Ti}_{3} \mathrm{C}_{2}$ has been extensively explored owing to a remarkable combination of high conductivity and hydrophilic properties, finding its use in many applications such as electrodes for Li-, Na-, and $\mathrm{K}$-ion batteries ${ }^{29,30}$ and supercapacitors ${ }^{31,32}$. There are currently over 200 different MXenes predicted, and about 30 of them have been realized experimentally, see figure 2.5. ${ }^{28}$ 
Most MXenes are synthesised by etching of bulk MAX powders and a select few have been grown as thin films. ${ }^{68}$ There are no reports on direct synthesis of MXenes without first producing a MAX phase and subsequent etching. Additionally, there are currently no reports on nonterminated MXenes.

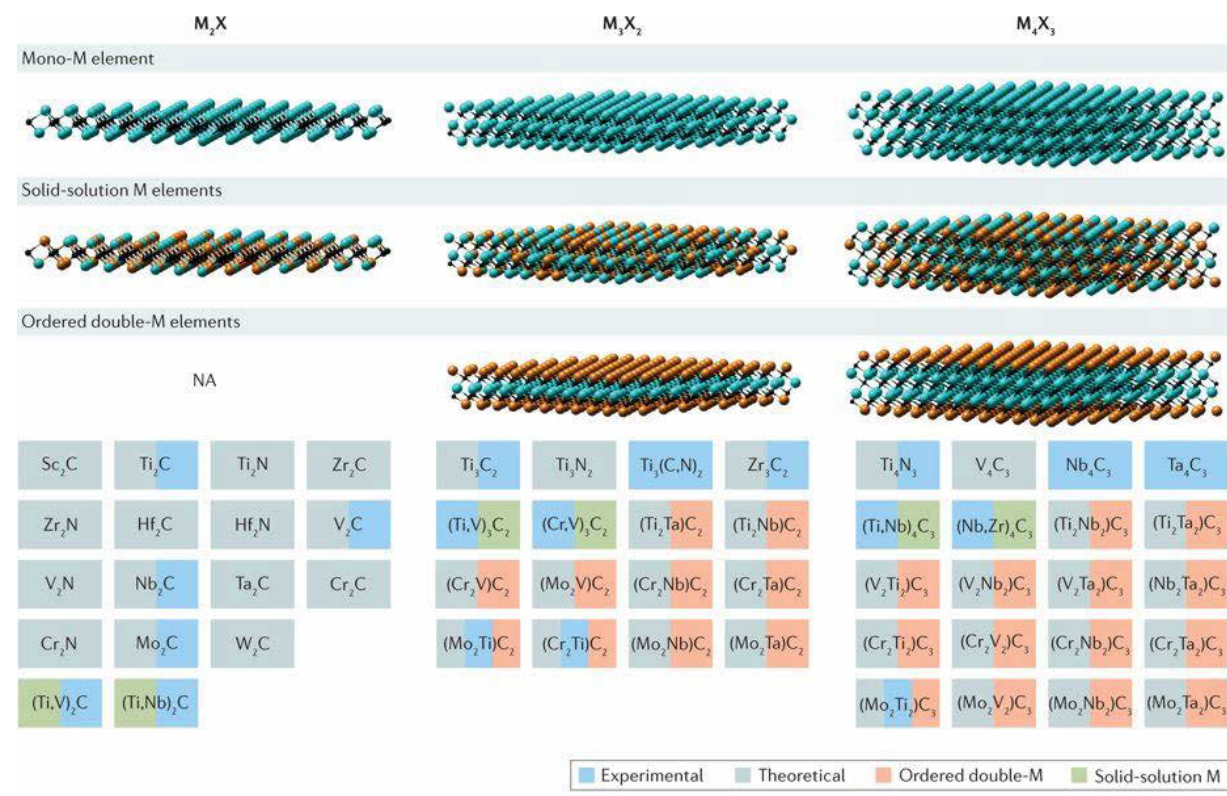

Nature Reviews | Materials

Figure 2.5: Illustration of the known MXenes and their structural classifications. Image adapted with permission. ${ }^{69}$ Copyright Springer Nature 2017.

\subsubsection{MAX powder synthesis and etching}

Fundamentally, MXenes are derived from MAX phases which are typically synthesised by solid state pressure-less sintering by mixing powders and heating at high temperatures in inert environment to prevent oxidation. ${ }^{19}$ Powders are filtered and mixed in ratios corresponding to the desired compound. During heating in a crucible, the particles coalesce and forms compounds. Sintering is a low-cost and scalable synthesis method and therefore highly advantageous for industrial use. The bulk 
MAX phase powders are then subjected to selective chemical etching, which results in removal of the relatively weakly bonded A layers while the MX layers are intact. Powders of pure $\mathrm{M}_{\mathrm{n}+1} \mathrm{X}_{\mathrm{n}} \mathrm{T}_{\mathrm{X}}$ (MXene) particles are formed after centrifuging, washing, filtering and drying the colloidal solution. ${ }^{20}$

In the case of $\mathrm{Ti}_{3} \mathrm{AlC}_{2}$, etchants like hydrofluoric acid (HF) or a combination of $\mathrm{LiF}$ and $\mathrm{HCl}$ salts in aqueous solution has been shown to react with the $\mathrm{Al}$ layers. Three main reactions have been proposed to be involved in Al removal and the origin of surface terminations and they are as follows:

$$
\begin{aligned}
& \mathrm{Ti}_{3} \mathrm{AlC}_{2}+3 \mathrm{HF}=A l F_{3}+\frac{3}{2} H_{2}+\mathrm{Ti}_{3} C_{2} \\
& \mathrm{Ti}_{3} \mathrm{C}_{2}+2 \mathrm{H}_{2} \mathrm{O}=\mathrm{Ti}_{3} \mathrm{C}_{2}(\mathrm{OH})_{2}+H_{2} \\
& \mathrm{Ti}_{3} \mathrm{C}_{2}+2 \mathrm{HF}=\mathrm{Ti}_{3} \mathrm{C}_{2} \mathrm{~F}_{2}+H_{2}
\end{aligned}
$$

Reaction (1) describes separation of $\mathrm{Al}$ from the MAX phase and the isolation of the MX sheets, by $\mathrm{AlF}_{3}$ and $\mathrm{H}_{2}$ formation. Reaction (2) and (3) are considered a natural consequence of dangling bonds of the bare $\mathrm{MX}$ surfaces reacting with the environment. As a result, a combination of $\mathrm{O}, \mathrm{OH}$ and $\mathrm{F}$ terminates the surfaces. ${ }^{20,21,22}$

\subsubsection{MAX thin film synthesis and etching}

A thin film is a term used to describe a very thin material, typically less than a few microns thick, that is place on top of a substrate material to alter its properties. In order to grow thin films with a desired crystalline structure, epitaxial growth is commonly employed. Epitaxy refers to growing a material of specific crystal structure on top of a template material (substrate) with a similar crystal, meaning the template structure is copied into the grown material. ${ }^{70}$ Sputtering is a PVD growth method that can be utilized to grow MAX phases epitaxially. The former involves the ejection of target ions from a solid onto a solid substrate by bombarding the target with high energy ions. Typically, Ar plasma containing neutral Ar, Ar ions, and free electrons is maintained in chamber. Ar ions from the plasma are accelerated to the target by a 
negative potential and the target ions are ejected by momentum transfer. Secondary electrons produced during ion bombardment of the target, assist in the ionization of neutral Ar in plasma as well as target ion condensation on the substrate surface and a film is grown. The etching procedure of thin films is similar to that of bulk powders; however, thin films require less time for complete $\mathrm{Al}$ removal. ${ }^{68}$

Thin film growth is more challenging than solid state pressure-less sintering in terms of growth optimisation due to the many more variables involved in the system. However, it is the method of choice when a welldefined orientated crystal over a large surface $(\mathrm{cm})$ is required for specific applications, e.g. semiconductors, optical devices.

\subsubsection{MXene intercalation and delamination}

Delamination enables a larger part of the surface accessible to the environment and that is useful in many applications. In order to delaminate MXenes, an energy barrier corresponding to the van der Waals forces between the adjacent MX sheets has to be broken. This barrier is relatively strong for MXenes (with their $\sim 2.2 \AA$ interlayer distance ${ }^{20}$ ) compare to for instance graphene, that has a $3.35 \AA$ separation between layers. ${ }^{2}$ A well-established method for increasing interlayer distance is intercalation. The latter is a term that refers to the introduction of external elements or molecules in between layers in a laminated material. Intercalation is used in for example ion-battery technology for charge (de-intercalation) and discharge (intercalation). When ions intercalate the interlayer distance increase, effectively reducing the energy required to delaminate the nanolaminar structure. It was shown that multi-layered $\mathrm{Ti}_{3} \mathrm{C}_{2} \mathrm{~T}_{\mathrm{X}}$ MXene exhibit surface plasmon screening effects rather than bulk plasmon excitation owing to the interaction between termination groups of adjacent layers. ${ }^{71}$ It was further suggested that the surface plasmon screening effects facilitates intercalation in MXenes.

Post HF etching, the multilayer MXene sheets are separated from each other by $\sim 2.2 \AA(1 \AA=0.1 \mathrm{~nm})$ as a result of the introduction of surface terminations in conjunction with intercalated $\mathrm{H}_{2} \mathrm{O} .{ }^{20}$ However, for 
further extension of interlayer distance and to facilitate complete delamination of the sheets, intercalation is required. Previous reports have observed an increase of the c-lattice parameter of MXenes after intercalation with TBAOH, DMSO, KOH, NaOH. ${ }^{72}$ Figure 2.6 illustrates the etching and intercalation effect on interlayer distances as well as the introduction of surface terminations.

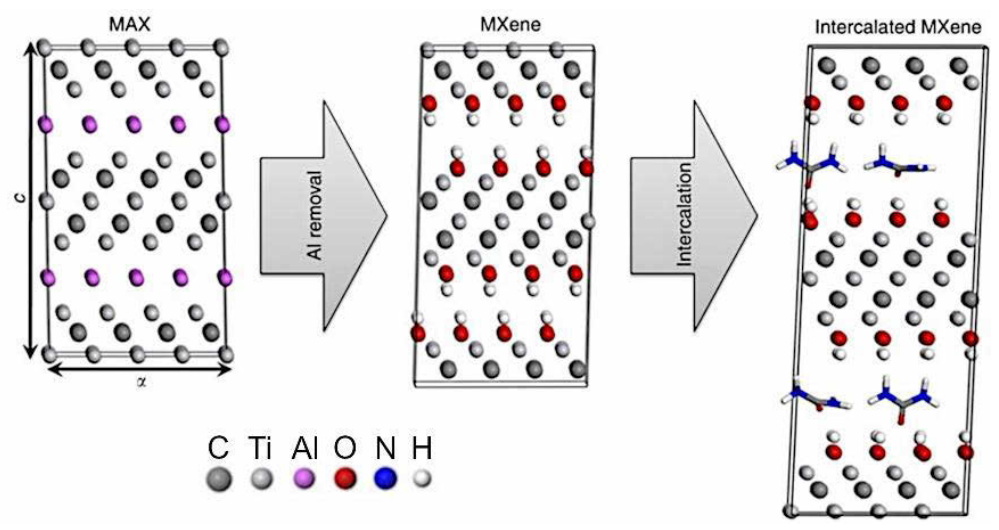

Figure 2.6: Illustration of etching procedure and the resulting $\mathrm{Ti}_{3} \mathrm{C}_{2} \mathrm{~T}_{\mathrm{X}}$ structure and a subsequent urea intercalation that increase the c-lattice parameter (interlayer distance). Adapted with permission. ${ }^{72}$ Copyright Springer Nature 2013.

A subsequent treatment by ultrasonication or in the case of $\mathrm{TBAOH}$, simple shaking, results in delamination on large scale. ${ }^{72}$ The delaminated single flake solution is centrifuged, washed and filtered and can be kept either in solution for a few days before degrading, depending on the MXene. Vacuum dried powder has an extended lifetime compared to aqueous solution and can last up to two weeks in ambient conditions. ${ }^{73,74}$ Recently, reports have shown an increased stability of delaminated MXenes up to 5 weeks in water-free environments, ${ }^{75}$ or up to 39 weeks stored at $-80{ }^{\circ} \mathrm{C} .76$ The degradation of MXenes in presence of water is a significant challenge for industrial applications, however, there are room for improvements. Notably, the properties presented in the next section are acquired from MXene prepared as discussed above but in addition a 
filtering step is employed, followed by compression into a thin paper or film.

The delamination method used for the experiments in this work consist of $\mathrm{TBAOH}$ intercalation post $\mathrm{HF}$ or $\mathrm{LiF}+\mathrm{HCl}$ etching, followed by gentle shaking. This produces large single flake MXene suspended in deaerated deionized water, that enables direct characterisation and full exploitation of both surfaces without the influence of intercalated molecules and or contaminants.

\subsection{MXene properties and applications}

Based on the number of publications focused on a specific property, the MXenes are considered highly promising in two primary topics, energy storage (591) and electronic properties (299). Beyond that, fields that have just emerged over the last two years are sensors (73), and magnetic properties (73), optical properties (65), and catalysis (36). Noteworthy, 436 out of total 1157 publications have investigated $\mathrm{Ti}_{3} \mathrm{C}_{2} \mathrm{~T}_{\mathrm{X}}$, the first and most convenient MXene to reproduce in large quantities (Source: web of science 2011-2019). The following sections gives an overview of MXene properties and how they are affected by the surface terminations.

\subsubsection{Energy storage}

Since the discovery of MXenes in 2011, ${ }^{20}$ energy storage has been their main application. In general, energy storage materials provide either a high energy density at the expense of power density (batteries) or vice versa (supercapacitors). The reason being, supercapacitors with high power densities consist of porous materials with a high surface area, ideal for ionic transport and adsorption on surface sites. Batteries, on the other hand, typically consist of materials that incorporates charge not only on surfaces but also by diffusion into interstitials driven by a potential, causing a phase transformation, and then contract when charge is released. That leads to higher energy densities, however, with a slower process for charge transport and consequently has a low power density. 77 
MXene has the potential to rapidly intercalate and de-intercalate ions in a dense layered matrix in conjunction with being able endure liquid salt and base electrolytes without degrading over thousands of cycles. Furthermore, they possess a large surface, metallic conductivity and low volume increase post intercalation and that has put MXenes in the spotlight for $\mathrm{Li}^{+},{ }^{20,78} \mathrm{Li}-\mathrm{S},{ }^{79,80}$ and $\mathrm{Na}^{+},{ }^{81,82} \mathrm{Mg}^{2+},{ }^{82} \mathrm{~K}^{+},{ }^{82} \mathrm{Al}^{3+} 83$ and $\mathrm{NH}^{4+},{ }^{82}$ batteries as well as for electrode materials in supercapacitors. ${ }^{7,84,85,86,87}$

The specific surface area and density of $\mathrm{Ti}_{3} \mathrm{C}_{2} \mathrm{~T}_{\mathrm{X}}$ post $\mathrm{HF}$ etching was measured to $\sim 23 \mathrm{~m}^{2} \mathrm{~g}^{-1}$ ( $\mathrm{N}_{2}$ adsorption isotherm) and $3.7 \mathrm{gcm}^{-3}$ respectively. Furthermore, a stable lithiation capacity of $120 \mathrm{mAhg}^{-1}$ at a rate of $0.2 \mathrm{mVs}^{-1}$ after 80 cycles ${ }^{20}$ and a volumetric capacity of $300 \mathrm{~F} \mathrm{~cm}^{-3}$ was reported ${ }^{7,84}$ Considering that those values were obtained without optimisation with respect to cation type, interlayer distance, porosity, surface $\mathrm{M}$ atoms type, defects, catalytic adatoms, and or surface terminations, that makes MXenes are excellent candidates for energy storage applications. The first report on significantly increased charge capacity for supercapacitors came in 2014, three years after the initial discovery, where a clay-like MXene was realized with a volumetric capacity of $\sim 900 \mathrm{~F} \mathrm{~cm}^{-3}$, surpassing state-of-the-art graphene-based supercapacitors $\left(376 \mathrm{~F} \mathrm{~cm}^{-3}\right) .{ }^{84}$ Further modification by mixing MXene and holey graphene was shown to increase volumetric capacitance to $1445 \mathrm{Fcm}^{-3}$ at $2 \mathrm{mVs}^{-1}$ with a surface area of $68 \mathrm{~m}^{2} \mathrm{~g}^{-1} .{ }^{85}$ Recently, a report on MXene derived porous carbon networks demonstrated a surface area of $1080 \mathrm{~m}^{2} \mathrm{~g}^{-1}$ and a corresponding volumetric capacity of $212 \mathrm{~F} \mathrm{~cm}^{-3}$ at $1 \mathrm{Ag}^{-1} .{ }^{86}$ To date, there are a lack of experimental works demonstrating the effect of surface terminations other than $\mathrm{O}, \mathrm{OH}$, and $\mathrm{F}$ (non-inherent terminations) on volumetric capacity.

\subsubsection{Electronic properties}

Most investigations on electronic properties of MXenes have been theoretical, out of which the main part have considered non-terminated or fully terminated surfaces by a single species. ${ }^{88,89,90,91,92,93,94}$ The non- 
terminated MXenes are predicted to be metallic, however, upon termination they become semiconducting, with bandgaps depending on the type of termination $(\mathrm{O}, \mathrm{OH}, \mathrm{F}) .{ }^{90}$ In addition, OH-terminated MXenes have been predicted as ultra-low work function electron emitters, which is promising for field effect transistors. ${ }^{89}$ Se figure 7 below.

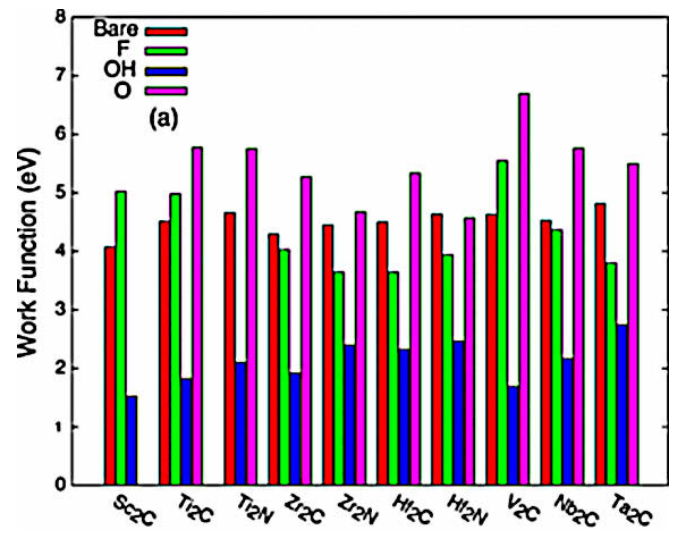

Figure 2.7: Predicted work functions for $\mathrm{M}_{2} \mathrm{X}\left(\mathrm{O}_{2}, \mathrm{OH}_{2}\right.$ or $\left.\mathrm{F}_{2}\right)$. Reused with permission. ${ }^{90}$ Copyright 2015, American Physical Society.

Adding to that, predictions also show that the density of states (DOS) at the fermi level of non-terminated single MXene sheets are higher than for the corresponding bulk MAX phase. Upon termination however, the DOS is again reduced. ${ }^{95}$ The proposed mechanism for reduced DOS at the fermi level in the MAX phase is charge transfer from $\mathrm{M}$ to $\mathrm{A}$ atoms (bands near the fermi level consists of transition metal d-bands). Nonterminated MXene are not affected by such a charge transfer as the A layer is removed. Terminated MXene is again affected by charge transfer from the more electronegative $\mathrm{O}, \mathrm{OH}, \mathrm{F}$ atoms and additional states are generated below the fermi level, thus reducing the DOS. ${ }^{97}$ Surface plasmon tuning was predicted for $\mathrm{Ti}_{3} \mathrm{C}_{2} \mathrm{~T}_{\mathrm{X}}$, depending on $\mathrm{OH}$ and $\mathrm{F}$ terminations combined with different thickness of MXene stacks.

In general, experimental electric measurements of MXene differ from predictions. For instance, a semiconducting MXene has not been experimentally verified. Additionally, electronic mobilities are measured 
lower than expected. The main arguments for the discrepancies are the observed combination of $\mathrm{O}, \mathrm{OH}$, and F-terminations, rather than the full exclusive coverage that most theoretical works has assumed. ${ }^{96}$ Another important effect that is in general not considered in many theoretical investigations are the influence of intercalated species. Intercalation of $\mathrm{H}_{2} \mathrm{O}$ and organic spacers have been reported during the delamination procedures, ${ }^{7}$ however to what extent electronic properties are affected by the intercalation has not been quantified experimentally. Recently, a theoretical approach on weighing different termination compositions and their effect on electronic properties showed a good agreement with experimental values. ${ }^{22}$ This indicates the importance for methods to tailor surface terminations on MXenes.

Bandgaps are essential for switching electronics. MXenes has been predicted to exhibit bandgaps for exclusively O-, OH-, and Fterminations, see Table 2.1. F-terminated MXenes show larger bandgaps (up to $1.35 \mathrm{eV}$ for $\mathrm{Cr}_{2} \mathrm{TiC}_{2} \mathrm{~F}_{2}$ ) while most O-terminated MXenes are semimetals.

However, experimental works on semiconducting MXenes are lacking, arguably because of the difficulty in producing exclusively terminated MXenes combined with unintentional intercalated $\mathrm{H}_{2} \mathrm{O}$ inducing metallic behaviour.

The high electric conductivity of MXenes renders them promising for electrode materials in e.g. batteries, supercapacitors, and electrolysis for water splitting. $7,20,40,86,87$

Table 2.1: Calculated bandgaps for MXenes with respective termination. (full exclusive coverage is assumed). Reused with permission. 96 Copyright 2018 Wiley-VCH. 


\begin{tabular}{|lccc|lccc|}
\hline MXene & $\mathbf{T}_{\mathbf{X}}$ & $\begin{array}{c}\text { Bandgap } \\
{[\mathbf{e V}]}\end{array}$ & $\mathbf{R e f}$ & MXene & $\mathbf{T}_{\mathbf{X}}$ & $\begin{array}{c}\text { Bandgap } \\
{[\mathbf{e V}]}\end{array}$ & $\mathbf{R e f}$ \\
$\mathrm{Sc}_{2} \mathrm{C}$ & $\mathrm{O}$ & 1.8 & 97 & $\mathrm{Mo}_{2} \mathrm{ZrC}_{2}{ }^{*}$ & $\mathrm{O}$ & 0.13 & 91 \\
& $\mathrm{~F}$ & 1.03 & 97 & $\mathrm{Mo}_{2} \mathrm{HfC}_{2}{ }^{*}$ & $\mathrm{O}$ & 0.24 & 91 \\
& $\mathrm{OH}$ & 0.45 & 97 & $\mathrm{~W}_{2} \mathrm{TiC}_{2}{ }^{*}$ & $\mathrm{O}$ & 0.29 & 91 \\
$\mathrm{Ti}_{2} \mathrm{C}$ & $\mathrm{O}$ & 0.24 & 97 & $\mathrm{~W}_{2} \mathrm{ZrC}_{2}{ }^{*}$ & $\mathrm{O}$ & 0.28 & 91 \\
$\mathrm{Zr}_{2} \mathrm{C}$ & $\mathrm{O}$ & 0.88 & 97 & $\mathrm{~W}_{2} \mathrm{HfC}_{2}{ }^{*}$ & $\mathrm{O}$ & 0.41 & 91 \\
$\mathrm{Hf}_{2} \mathrm{C}$ & $\mathrm{O}$ & 1.0 & 97 & $\mathrm{Hf}_{2} \mathrm{MnC}_{2}$ & $\mathrm{O}$ & 0.24 & 100 \\
$\mathrm{Cr}_{2} \mathrm{C}$ & $\mathrm{F}$ & 3.49 & 98 & & $\mathrm{~F}$ & 1.03 & 100 \\
& $\mathrm{OH}$ & 1.43 & 98 & $\mathrm{Hf}_{2} \mathrm{VC}_{2}$ & $\mathrm{O}$ & 0.06 & 100 \\
$\mathrm{Mo}_{2} \mathrm{TiC}_{2}{ }^{*}$ & $\mathrm{O}$ & 0.12 & 91 & $\mathrm{Cr}_{2} \mathrm{TiC}_{2}$ & $\mathrm{~F}$ & 1.35 & 101 \\
& $\mathrm{~F}$ & 0.5 & 99 & & $\mathrm{OH}$ & 0.84 & 101 \\
& $\mathrm{OH}$ & 0.05 & 99 & $\mathrm{Hf}_{3} \mathrm{C}_{2}$ & $\mathrm{O}$ & 0.16 & 102 \\
& & & & & & &
\end{tabular}

Furthermore, the conductivity dependence with intercalants enables their use in electromagnetic interference shielding (EMI), ${ }^{103}$ figure 2.8 demonstrates EMI dampening as a function of $\mathrm{Ti}_{3} \mathrm{C}_{2} \mathrm{~T}_{\mathrm{X}}$ film thickness.

In addition, the high conductivity of MXenes also renders them promising for high sensitivity sensor applications ${ }^{104}$ as well as in flexible conducting thin films. ${ }^{105}$ Initial reports on electric conductivity yielded a low value of $0.147 \mathrm{Scm}^{-1}, 106$ while after optimisation of flake sizes, flake alignments, defects, etc. by altering preparation methods, values up to $9880 \mathrm{Scm}^{-1}$ have been achieved. 107 
a)

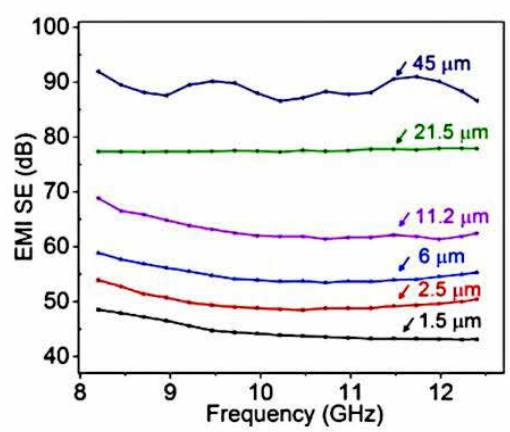

b)

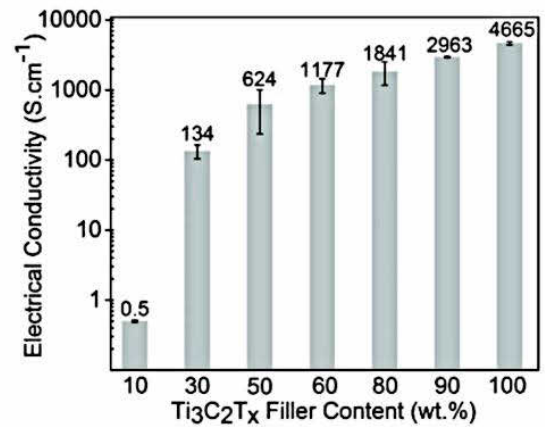

Figure 2.8. a) EMI shielding as a function of $\mathrm{Ti}_{3} \mathrm{C}_{2} \mathrm{~T}_{\mathrm{X}}$ film thickness caused by intercalation of $10 \mathrm{wt} . \%$ sodium alginate fillers. b) Conductivity of $\mathrm{Ti}_{3} \mathrm{C}_{2} \mathrm{~T}_{\mathrm{X}}$ as a function of filler content. Reused with permission. ${ }^{103}$ Copyright AAAS 2016.

Moreover, like many other 2D materials, MXenes exhibit anisotropic conductivity when stacked. Conductivity within a sheet (in-plane) is relatively high, while the conductivity across adjacent sheets (out-ofplane) is low. ${ }^{96}$ The out-of-plane conductivity was suggested to have an interflake hopping behaviour, owing to interactions between surface terminations and intercalated molecules. In contrast, in-plane (intraflake) conductivity depends on the surface $\mathrm{M}$ - and $\mathrm{X}$-atoms, and the $\mathrm{M}-\mathrm{T}_{\mathrm{X}}$ bond. ${ }^{107}$ Again, an indication of the importance of the effect of terminations on electronic properties.

\subsubsection{Adsorption properties}

Adsorption of single molecules for catalytic and/or high sensitivity sensing purposes is a field that has receive significant attention the last years.

Adsorbed water on $\mathrm{Ti}_{3} \mathrm{C}_{2} \mathrm{~T}_{\mathrm{X}}$ MXene was found to alter transport properties in such a degree that it could be used for ultra-sensitive humidity detectors. ${ }^{108}$ Moreover, efficient $\mathrm{CO}_{2}$ adsorption was predicted on non-terminated ${ }^{26,27}$ as well as for $\mathrm{O}$ - and $\mathrm{OH}$-terminated MXenes. ${ }^{27}$ In the case of non-terminated MXene, spontaneous chemisorption was favourable and suggested as a route to $\mathrm{CH}_{4}$ conversion applications. ${ }^{27} \mathrm{O}-$ and $\mathrm{OH}$-terminated MXenes, on the other hand, showed non-spontaneous 
physisorption with energy barriers of $0.23 \mathrm{eV}$ and $0.35 \mathrm{eV}$, respectively. However, posterior to adsorption, a spontaneous $\mathrm{CH}_{4}$ conversion cycle was suggested favourable after protonation steps. ${ }^{27} \mathrm{Cl}$-adsorption on $\mathrm{Ti}_{2} \mathrm{CT}_{\mathrm{X}}$ was investigated theoretically and found promising for $\mathrm{Cl}$-ion batteries with a specific capacitance of $331 \mathrm{mAhg}^{-1} .{ }^{109}$ Furthermore, Sterminated MXene have been investigate theoretically for $\mathrm{Na}$-ion applications with an estimated specific capacity of $463 \mathrm{mAhg}^{-1}$. However, there is a lack of experimental reports on non-inherent terminations on MXenes.

\subsection{Modification of surface chemistry}

MXenes have been considered promising for a wide range of applications, because of their rich chemical diversity. Interestingly, MXenes with different transition metals show smaller variation in electronic properties (e.g. mobility, bandgap) than the same MXene but with different termination composition. On that account, a detailed knowledge on the surface chemistry is required for any attempt on designing MXene properties.

It is well established that the surface terminations depend on the synthesis conditions, e.g., the etchant, the surface M layers, and storage conditions. All of the MXene properties discussed in previous sections are largely determined by the chemistry of the terminations. For that reason, many previous works have covered etching of MAX phases using different procedures, and ending up in a variety of $\mathrm{O}, \mathrm{OH}$, and $\mathrm{F}$ combinations. $\mathrm{O}$ and $\mathrm{OH}$ ratios have been remarkably difficult to distinguish experimentally, arguably because of influence of intercalated water.

The most common method of determining the composition of surface terminations have been curve fitting of $\mathrm{x}$-ray photoelectron spectroscopy (XPS) data, ${ }^{110}$ which is further discussed in the next chapter. In addition, x-ray and neutron scattering atomic pair 
distribution function have been used for modelling the surface terminations. However, that requires assumptions on the model used to fit the data and more importantly, challenges arise when attempting to distinguish OH-terminations from $\mathrm{OH}$ in intercalated $\mathrm{H}_{2} \mathrm{O}$. Recently, a direct quantitative approach using nuclear magnetic resonance (NMR), which is a technique sensitive to hydrogen, ${ }^{111}$ was used to characterise MXene terminations, showing a much lower $\mathrm{OH}$ content than previous estimates. ${ }^{21}$

Up till now, there are few reports on post synthesis termination modification. One group reported on replacement $\mathrm{O}-$ to $\mathrm{OH}-$ terminations after treatment in $\mathrm{KOH}$, however with a large amount of $\mathrm{TiO}_{2}$ present. ${ }^{112}$ Furthermore, one report on thermal treatment of $\mathrm{Ti}_{3} \mathrm{C}_{2} \mathrm{~T}_{\mathrm{X}}$ in $\mathrm{N}_{2}-\mathrm{H}_{2}$ environment up to $300{ }^{\circ} \mathrm{C}$ claiming an improved capacity due to increased carbon content and reduced $\mathrm{Ti}, \mathrm{O}$ and $\mathrm{F}$ content, however it was unclear if the final structure was a MXene. 113 One report on thermal and electronic bias treatments to reduce the amount of O-terminations on $\mathrm{Mo}_{2} \mathrm{Ti}_{2} \mathrm{C}_{3} \mathrm{~T}_{\mathrm{X}}$, while the number of Oterminations remained constant for a $\mathrm{Ti}_{3} \mathrm{C}_{2} \mathrm{~T}_{\mathrm{X}}$ sample. ${ }^{114}$ Reduction of $\mathrm{Ti}_{3} \mathrm{C}_{2} \mathrm{~T}_{\mathrm{X}}$ was reported by employing solution heating in lithium ethylenediamine. A mechanism was proposed for partial O substitution of $\mathrm{C}$ positions and $\mathrm{O}$ vacancy formation, based on XPS curve fitting of $\mathrm{Ti}^{3+}$ and $\mathrm{Ti}^{4+} .{ }^{115} \mathrm{~A}$ theoretical investigation suggested a route for realizing non-terminated MXenes by repetitive photocatalytic protonation of $\mathrm{O}$ and $\mathrm{OH}$-terminations, ${ }^{27}$ however, experimental reports on fully covered single species terminations or non-terminated MXene are lacking. 
24 


\section{Characterization}

Surfaces of any material are challenging to characterize because of surface reactions with the environment influencing the data analysis. To rule out the effect of contaminants, typically in situ techniques are used. In situ refers to "on site" and for experimental purposes the term means stimulation of materials inside a characterization system. In the case of hydrocarbon contamination (typically occurs in a TEM), it may involve thermal treatment, biasing or sputtering preceding a measurement, eliminating the need for exposing the materials to ambient conditions due to transfers between systems. This work has focused on characterizing freestanding MXene sheets which consists of two surfaces separated by up to $1 \mathrm{~nm}=10 \AA$ or about 7 atomic layers thick. A rough estimate for contamination build-up in a vacuum environment is about 1 atomic layer per minute at $10^{-7} \mathrm{mbar}=10^{-5} \mathrm{~Pa},{ }^{117}$ which is the typical working pressure in a TEM.

It is therefore essential to use characterization techniques that; (1) is sensitive enough for such a small volume of material and can distinguish atomic variations in chemistries on said surface spectrally and or locally, (2) has in situ methods for dealing with surface contaminations, and (3) can provide direct evidence of surface arrangements with limited use of models based on assumptions. To elaborate on (1), most characterization techniques probes the material on a large scale, i.e. visible light or x-ray probes are typically on the $\mathrm{mm}$ range. That renders the information acquired an average of the local atomic arrangements. 
Techniques such as atomic force microscopy (AFM) ${ }^{118}$ or scanning tunnelling microscopy (STM) 119 are frequently used to characterize surfaces on the atomic scale however quantitative methods for elemental identification are lacking. For precise atomic characterization, smaller probes with quantitative potential are required. Point (3) is especially important for MXenes owing to the many compositional and structural variables that exists for the compound, the terminations and the intercalants which present a significant challenge when modelling.

TEM can provide a probe of a size comparable to the width of an atom and at the same time offers quantitative imaging and spectroscopy modes, for elemental characterization. For that reason, TEM has been the main characterization technique in this project. The next section will give a detailed review of TEM and how it can be utilized to investigate MXenes. Notably, TEM provides local information, therefore, in order to form a complete large-scale picture of materials properties other techniques needs to be combined. For example, XPS and/or RGA was further employed to in papers 1, 2 and 3, and will be discussed further in sections 3.9 and 3.10 .

\subsection{Transmission electron microscopy}

In an electron microscope, electrons are used to form a projected picture of a material, in contrast to visible light used in conventional visible light microscopes. The inventors, Ruska and Knoll was awarded the Nobel prize in 1986 for their accomplishment. ${ }^{120}$ The main advantage of using electrons instead of light is that atomic size features may be observed using electrons because of the shorter wavelengths available to electrons. This is called the resolving power of a microscope, and the most common way of describing image resolution, is demonstrated by the Rayleigh wave front criterion, 121

$$
d=\frac{0.61 \lambda}{\mu \sin \beta}
$$


where $\lambda$ is wavelength of the probe, $\mu$ is the refractive index, and $\beta$ is the semi-angle of magnification. This equation translates into the smallest observable distance between two point objects in a diffraction pattern, specifically, when one object is centred at the first minima of the other object, see figure 3.1 .

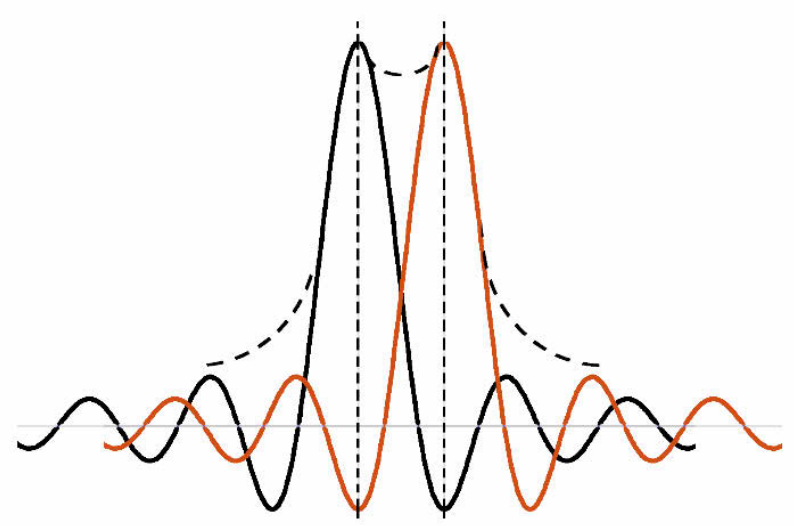

Figure 3.1. Point resolution according to the Rayleigh wave front criterion. ${ }^{121}$ The two objects are resolved only if the second object (red) is centred no closer than first minima of the first object (black), see dashed lines.

The wavelength of visible light is between 400-750 $\mathrm{nm}$ which typically results in a so-called point resolution of about half the wavelength of the light. Hence, conventional microscopes can only resolve features larger than 200-400 nm. For the electrons however, the wavelength is determined by the de Broglie relation,

$$
\lambda=h / p
$$

where $h$ is the Planck's constant, and $\mathrm{p}$ is the momentum. Accordingly, the wavelength of and electron probe is given by the acceleration potential of the TEM, typically between 40 and $300 \mathrm{kV}$. The wavelength of an electron probe is therefore on the order of a few picometers $\left(10^{-12} \mathrm{~m}\right)$, which is $10-50$ times less than the width of an atom. Unfortunately, the point resolution of an electron microscope is considerably worse, mainly because of electromagnetic lens aberrations, 
122 which will be discussed further on. The other main figures of merit for electron microscopes are energy resolution and coherence. The former is the measure of the accuracy of the electron energy, generated by the acceleration potential combined with the spread of excitation energy of the gun. Coherence refers to the collective phase and direction of the electron beam along an optical axis.

In a TEM the electron beam is generated by an electron gun, transmitted through a thin sample, typically less than $100 \mathrm{~nm}$ thick, to allow electrons to pass through, and the image of the sample is projected onto a detector. 2D materials are therefore ideal for TEM investigations owing to their thin nature. The space required for all the components comprising a TEM sums up to several meters. Sending electrons over such a distance is only possible if a very high vacuum is maintained all through the microscope, to reduce the probability of electrons scattering on molecules and losing intensity, energy and coherence on their way to the sample and detector. As a consequence of the vacuum environment and thickness limit of a TEM sample, special preparation methods are required for TEM measurements. Up until recently, vacuum compatibility was one of the requirements for TEM samples, however, with recent developments in in situ TEM techniques there are ways around this requirement, more details will be given on in situ TEM in section 3.6.

\subsubsection{Principles of TEM}

A TEM can be sectioned into two main parts, the illumination system and the imaging system, see figure 3.2. Electrons, contrary to photons, cannot be focused or spread by conventional optical lenses. However, the electron path can be controlled by electromagnetic lenses, as the electrons are negatively charged particles and therefore are affected by magnetic and electric fields according to the Lorentz equation.

$$
\boldsymbol{F}=q(\boldsymbol{v} \times \boldsymbol{B}+\boldsymbol{E})
$$


where $\boldsymbol{F}$ is the force vector exerted upon the electron, $q$ is charge of the particle, $\boldsymbol{v}$ is the velocity vector, $\boldsymbol{B}$ is the magnetic field vector, and $\boldsymbol{E}$ is the electric field vector. In principle, the electrons do not follow a straight path, but is rather focused helically toward the optical axis, however, for simplicity all schematics will approximate the electron beam to a straight line. The illumination system constitutes the electron gun, the accelerator and the condensing lenses which has the purposes of producing either a spread beam for conventional TEM (CTEM) or a focused probe for STEM. The imaging system contains the objective lens and the projection lenses and the detectors.

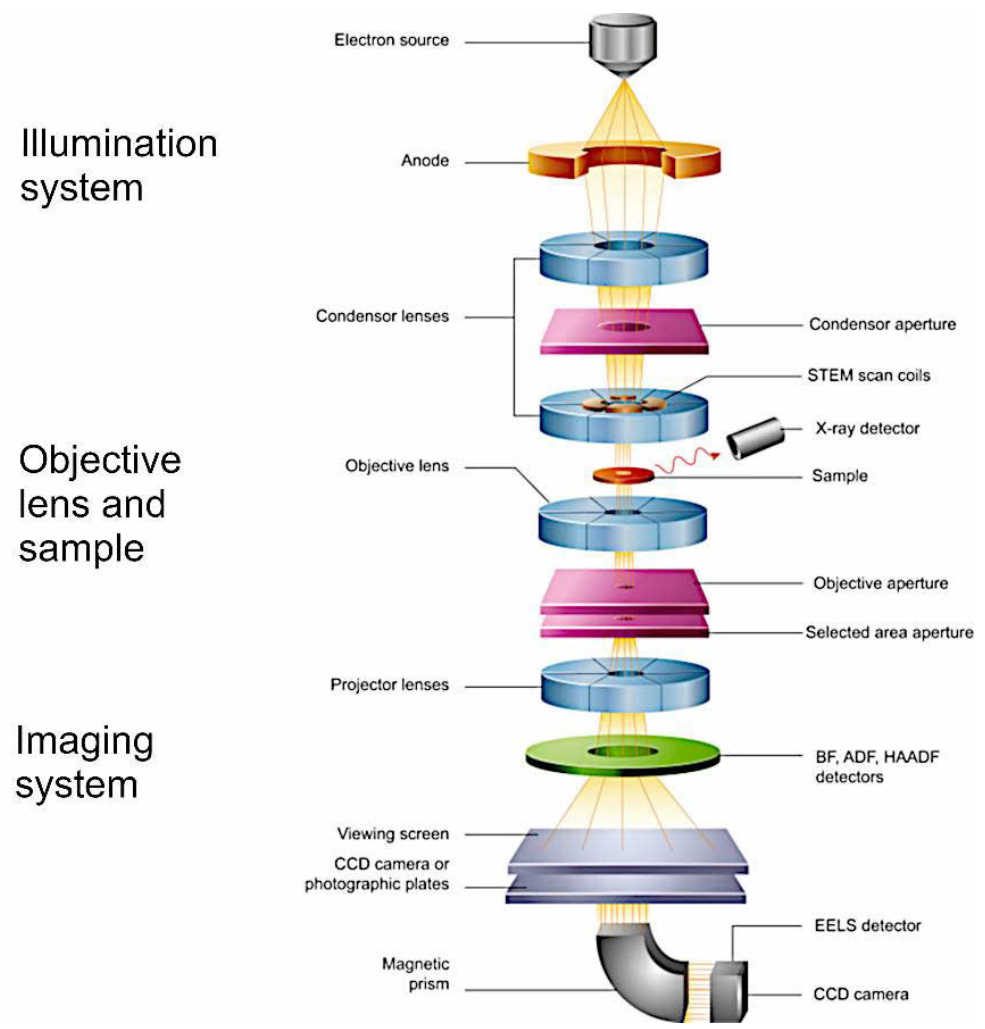

Figure 3.2. Schematic of a typical TEM system. An electron gun generates a spread beam that is accelerated and then focused onto the optical axis by a condenser system. Scan coils above the sample are used for STEM mode. The objective lens forms the image and the imaging system projects and magnifies the image onto a detector. Reused with permission from ${ }^{123}$. Copyright Elsevier. 
Modern TEMs employs field emission electron guns (FEGs), 117 comprising of a very thin tip that emits electrons only from its top surface, generating a beam with a low energy spread and high coherence. This is managed by heating the tip well below thermal emission temperatures of the tip and then applying and extraction potential that allows electrons only from the very tip to be emitted by tunnelling. The heating also reduces probability of contamination and degradation of the tip. ${ }^{117}$ Subsequently, the electron beam enters the accelerator which applies stage-wise acceleration of the electrons up to the working potential of the microscope with a high energy stability. The resulting high energy beam is then collected and focused on the optical axis by the condenser system. In this work a high brightness Schottky field emission gun (XFEG) was employed with an energy resolution of $\sim 1.2 \mathrm{eV}$ at $300 \mathrm{kV}$ acceleration potential.

The lower condenser lens (or upper objective lens depending on denomination) provides parallel illumination on the specimen in the case of CTEM imaging, and for STEM mode a converged probe is focused on the specimen and the scan coils are activated, enabling raster imaging. The degree of convergence is set by the condenser aperture (see figure 3.2) and is important for image contrast and will be discussed in section 3.1.3.

The objective lens is situated directly below the sample and its purpose is to form the image. Consequently, defects (unavoidable with the present technology) in the objective lens induce aberrations in the image that is further magnified by the projection system. ${ }^{117}$ The objective lens is therefore the limiting component of a TEM and recent developments in electron microscopy has been centred on correcting the aberrations of the objective lens. ${ }^{117}$ Aberrations will be further explained in section 3.1.2 and the correction procedures in section 3.1.4.

The objective aperture is a mask located in the diffraction plane and is used to project only specific set of frequencies in the diffraction pattern, called bright field or dark field mode, more details on that topic is given 
in section 3.1.3. The selected area aperture is used to mask out areas in the image plane.

The projection lenses are used to magnify the image and project it at different camera lengths (distance between sample and detector), providing contrast in for example high angle annular dark field (HAADF) STEM. Furthermore, the projection lenses are used to select if the image plane or the cross-over plane (diffraction pattern) is projected on the detector. The imaging system also includes detectors of various types.

In this work, a FEI Titan ${ }^{3}$ TEM operated at $300 \mathrm{kV}$ was employed, equipped with a high brightness XFEG, a monochromator, probe and image aberration correctors, a FEI HAADF STEM detector, used for Zcontrast imaging, the charged couple device (CCD) camera, used for CTEM imaging, and the image filter detector used to collect EELS data and form spectrum images. In addition, in paper 2 a complementary metal oxide semiconductor (CMOS) camera was used for HRTEM imaging.

\subsubsection{Electron scattering}

Most of the electrons passing through a thin TEM sample are not scattered, those electrons are referred to as the direct beam. However, for the electrons that do scatter, two primary scattering mechanisms determines how the electrons interact with an atom, namely, elastic scattering (ES) and inelastic scattering (IES). ${ }^{117}$ The former refers to electrons scattering at an angle (1-10 ${ }^{\circ}$ in TEM) after interaction with a nucleus or an electron with no energy-loss. However, only the electron nucleus scattering is of importance for TEM imaging. The angle and probability of ES is given by the Rutherford equation. ${ }^{124}$ Modified Rutherford equations are typically used to describe the angle and probability of scattering in a TEM, which is the main contribution to image contrast in STEM, see eq. 3.3.

$$
\theta=\frac{0.117 Z^{1 / 3}}{E^{1 / 2}}
$$




$$
\sigma=1.62 * 10^{-24}\left(\frac{Z}{E}\right)^{2} \cot ^{2} \frac{\theta}{2}
$$

where $\theta$ is the angle of scattering, $\sigma$ is the probability of scattering, $\mathrm{Z}$ is the atomic number of the nucleus, and $\mathrm{E}$ is the electron energy. Diffraction is an ES mechanism that occur when the electrons (having the property of quantum mechanical waves) are incident on periodically spaced slits (lattice spacings in a crystal), resulting in an interference pattern, aka diffraction pattern. ${ }^{117}$ Eq. (3.5) describes scattering by diffraction in a crystal lattice.

$$
n \lambda=2 d \sin \theta_{B}
$$

where $n$ is an integer for the nth order scattering, $\lambda$ is the wavelength, $d$ is the lattice plane spacing, and $\theta_{B}$ is the Bragg angle of diffraction $\left(<1^{\circ}\right.$ in TEM), see figure 3.3. ${ }^{117}$

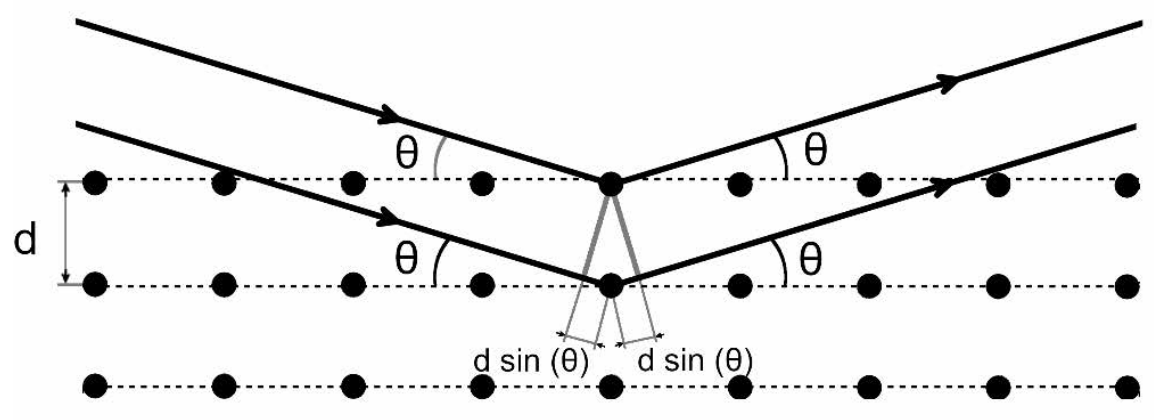

Figure 3.3. Schematic of Bragg's law of diffraction.

The diffraction pattern is used to characterize the structure of a crystal and to orient the sample, which will be discussed in more detail section 3.8. IES in a TEM occur at angles $<1^{\circ}$ when electrons lose energy by exciting; electrons bound to the nuclei, collective electron clouds (bulk and/or surface plasmons), and phonons. ${ }^{117}$ Additionally, electrons may also displace atoms by momentum transfer, causing damage to the 
sample, ${ }^{125}$ which is especially important to avoid for 2D materials characterization. IES is the main mechanism to investigate the chemistry of elements in a TEM by employing spectrometers that measures; the energy-loss of electron to identify atomic species, and/or the characteristic $\mathrm{x}$-rays emitted from the sample. The probability of scattering significantly affects quantification of CTEM and STEM images as well as EELS and x-ray spectra. Electrons may interact multiple times with atoms and electrons when passing through a thick material, resulting in double diffraction and multiple plasmon energy losses, which must be taken into account when applying quantitative models. Furthermore, electron beam channelling caused by coulombic attraction of the electron beam toward atomic columns in a crystal, results in higher probability of scattering at high angles than predicted by the Rutherford equation, consequently affecting quantification. ${ }^{126}$

\subsubsection{Image contrast}

Electrons are quantum mechanical objects which means they exhibit an amplitude and a phase. Each give rise to different contrast mechanisms. The intensity difference of two neighbouring areas defines the contrast in a TEM image. The differences may arise because of mass and/or thickness variation in the two areas, resulting in amplitude variations, called mass-thickness contrast and it is caused by the Z-dependence in eq. (3.4). A higher mass and an increased thickness results in a higher probability of scattering and a reduction of intensity in CTEM images, while an increase in intensity in STEM images. Furthermore, structural variations in the two areas leads to diffraction contrast which can be enhanced by the objective aperture by masking out the diffraction pattern except for specific diffraction angles resulting in dark field imaging (DF). In this imaging mode areas where electrons are scattered more strongly appear bright, and areas where electrons are not scattered appear dark. If the direct beam is allowed to pass through by the objective aperture, a bright field (BF) image is formed instead. 
Phase contrast imaging, or high resolution TEM (HRTEM) employs a contrast mechanism that is dominating when a very thin sample is subjected to an electron beam with high coherency and energy resolution. The phase difference of the diffracted beams, caused by the sample as the electrons are passing through, and the direct beam (exhibiting the original phase of the beam) give rise to interference and thereof phase contrast. ${ }^{117}$ Preceding aberration correctors, phase contrast imaging was the imaging mode with the highest achievable resolution, however after the introduction of probe correctors, the achievable resolution in HRSTEM is on par with HRTEM.

Beyond the contrast provided by the sample, the apertures, the objective lens aberrations, and the instabilities of the microscope transforms the image contrast, this effect is called the contrast transfer function. ${ }^{117}$ The effect of the spherical aberration, $\chi(\boldsymbol{u})$, as a function of spacial frequency on the image contrast can be described by Eq. (3.6),

$$
\chi(\boldsymbol{u})=\pi \Delta f \lambda u^{2}+\frac{1}{2} \pi C_{S} \lambda^{3} u^{4}
$$

where $\Delta f$ is the defocus, $\lambda$ is the wavelength, and $C_{S}$ is the spherical aberration coefficient. The $\mathrm{C}_{\mathrm{S}}$ envelope function describes the dampening effect of defocus spread caused by chromatic aberrations $\left(\mathrm{C}_{\mathrm{C}}\right)$, the current and acceleration instabilities, and the energy spread of the beam,

$$
E_{S}(\boldsymbol{u})=e^{-\left(\left(\frac{\pi \alpha}{\lambda}\right)^{2}\left(c_{S} \lambda^{3} \mathbf{u}^{3}+\lambda u\right)\right)},
$$

where $\alpha$ is the semi-angle of a gaussian source (FEG). Combining eqs. (3.6) and (3.7) results in contrast reversals as a function of spatial frequency, defocus and spherical aberration of the microscope, see figure 3.4 . 

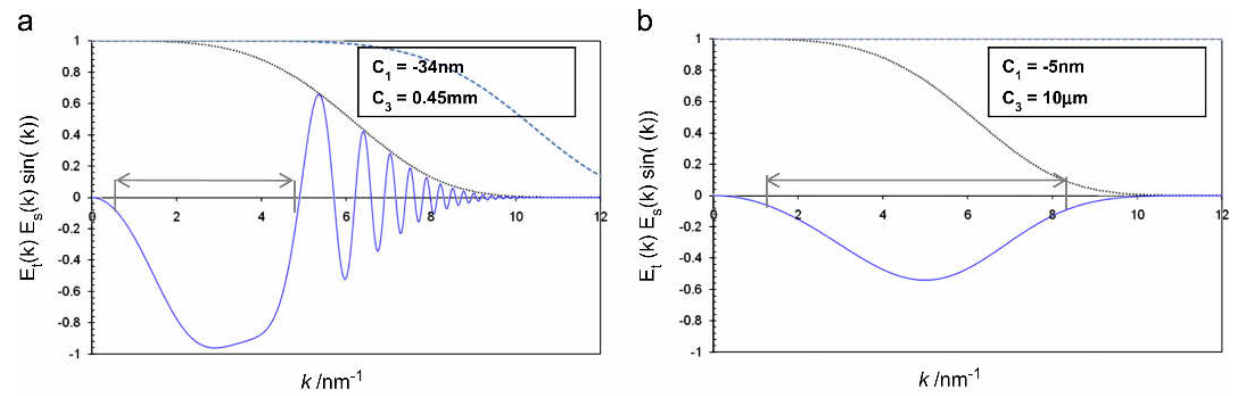

Figure 3.4. Contrast transfer functions for a JEOL 2200MCO (S)TEM, $200 \mathrm{kV}$, defocus spread $=3.8 \mathrm{~nm}$ microscope for a) a defocus of $\left(\mathrm{C}_{1}=34 \mathrm{~nm}\right)$ and spherical aberration $\left(\mathrm{C}_{3}=0.45 \mathrm{~mm}\right)$ and $\left.\mathrm{b}\right)\left(\mathrm{C}_{1}=-5 \mathrm{~nm}\right)$ and $\left(\mathrm{C}_{3}=10 \mu \mathrm{m}\right)$. Adapted with permission from ${ }^{127}$. Copyright 2013 Elsevier.

Notably, the contrast reversals visible in figure $3.4 \mathrm{a}$ is absent in figure $3.4 \mathrm{~b}$, this is an effect of the corrected spherical aberration $\left(\mathrm{C}_{\mathrm{S}}=10 \mu \mathrm{m}\right)$.

\subsubsection{Aberrations and correctors}

The point resolution of a modern TEM with uncorrected aberrations is about $2 \AA$, which allows for some lattice distances to be resolved, however not atomic resolution. With spherical aberration correction the resolution of a CTEM can be pushed down to $\sim 0.5 \AA$, and atomic resolution can be achieved. ${ }^{128}$ In this work, atomic resolution imaging is required to map out termination sites of MXenes, thereof follows a review on aberrations and how correction is performed.

The main resolution limiting aberrations in a TEM are spherical aberration $\left(\mathrm{C}_{\mathrm{S}}\right)$, chromatic aberration $\left(\mathrm{C}_{\mathrm{C}}\right)$, astigmatism $(\mathrm{A})$, and coma (B). Spherical aberration originates from the spherical shape of the objective lens generating field lines with reduced field strength closer to the optical axis, see figure 3.5. Electrons with trajectories further away from the optical axis will be focused at different points than trajectories close to the optical axis, resulting in focal spread. ${ }^{129}$ 


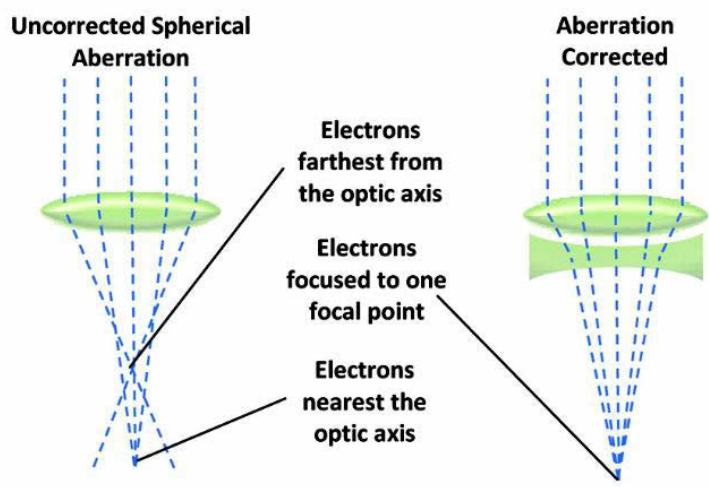

Figure 3.5. Spherical aberration induced electron trajectories and correction principle. Adapted with permission from ${ }^{129}$. Copyright 2010 American Chemical Society.

In order to correct for the focal spread caused by spherical aberration a set of correction lenses are added with conjugate aberrations, that counteract the effect of the aberrations in the first lens. ${ }^{130,131,132}$ In papers 2 and 3, CTEM imaging was employed with $\mathrm{C}_{\mathrm{S}}$ correction of the objective lens, enabled by a DCOR image corrector, situated below the objective lens. Papers 1, 4, 5, and 6 utilizes STEM imaging, where the $\mathrm{Cs}_{\mathrm{S}}$ of the objective lens do not affect image formation, however, $\mathrm{C}_{\mathrm{S}}$ of the converged probe coming from the condenser system was corrected by a DCOR probe corrector situated above the scan coils.

The procedure for correcting $\mathrm{C}_{\mathrm{S}}$ differs in CTEM and STEM, as well as for different corrector types. In CTEM mode the DCOR image corrector software takes a set of images of a defocused amorphous sample, measures the intensity distribution in the fourier transform (FT) of the image for different beam tilts (Zemlin tableau), and estimates the contribution of respective aberration, see figure 3.6. 

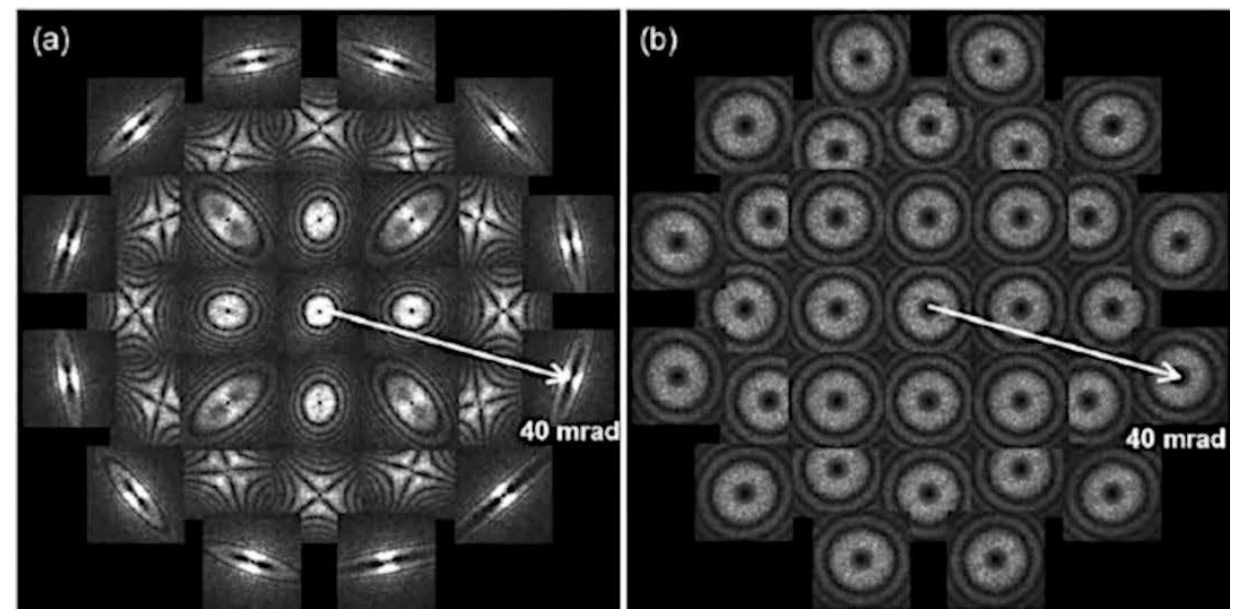

Figure 3.6. Estimation and correction of aberrations using a Zemlin tableau, consisting of tilt series of FT CTEM images of a defocused amorphous sample. An uncorrected Zemlin tableau is presented in a) and b) shows a corrected tableau. Reused with permission. ${ }^{133}$ Copyright 2013 Oxford university press.

In contrast, the DCOR probe corrector utilizes the convolution of STEM images acquired from a polycrystal sample in slight overfocus and underfocus and estimates the difference in the probe shape for different beam tilts, see figure 3.7 .

Chromatic aberration occurs when electrons with different energies are focused on different points on the optical axis. Correcting chromatic aberration has proved more difficult than spherical aberration, as static electric fields of the lenses induce further chromatic errors, however, $\mathrm{C}_{\mathrm{C}}$ correctors are available commercially. ${ }^{129}$ 


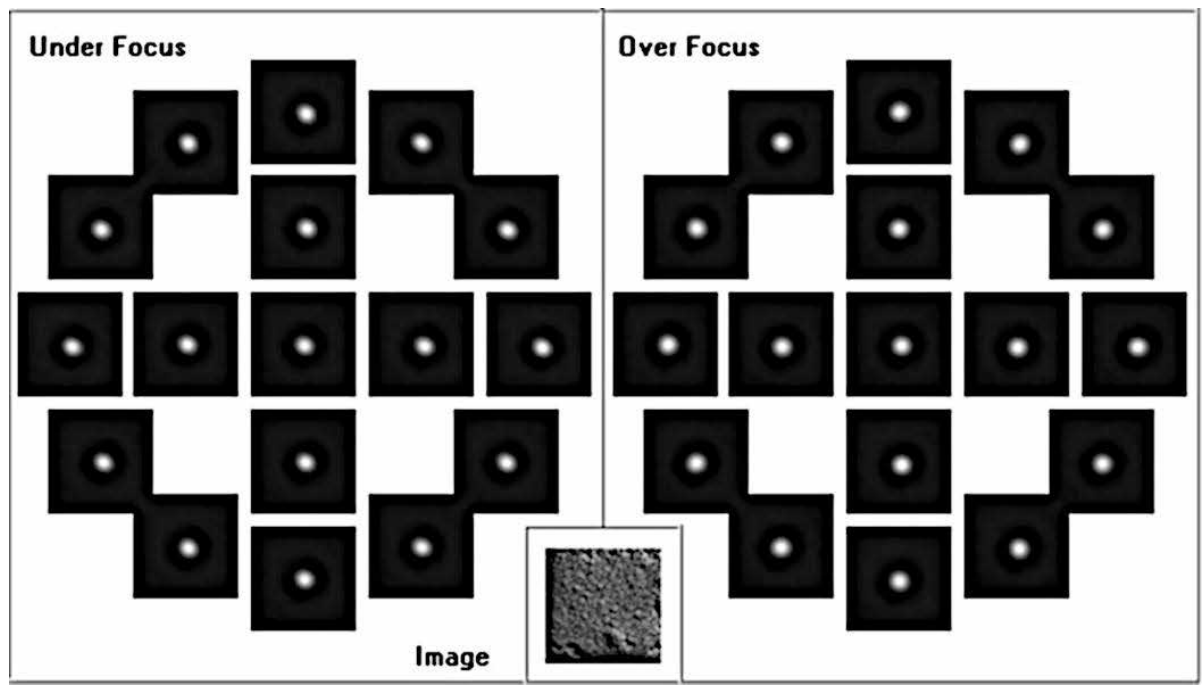

Figure 3.7. Zemlin tableau for STEM tilt series showing the deconvolved probe from a polycrystal sample. Reused with permission. ${ }^{134}$ Copyright Hsiao et.al., licensee Springer. 2014.

After $\mathrm{C}_{\mathrm{S}}$ have been corrected, $\mathrm{C}_{\mathrm{C}}$ is the main resolution limiting aberration. Eq. (3.8) describes the effect of $\mathrm{C}_{\mathrm{C}}$ on the defocus spread $\left(\Delta_{S}\right)$ of the electron beam.

$$
\Delta_{S}=\mathrm{C}_{\mathrm{c}} \sqrt{\left(\frac{\Delta \mathrm{I}}{I}\right)^{2}+\left(\frac{\Delta \mathrm{E}}{V}\right)^{2}+\left(\frac{\Delta \mathrm{V}}{V}\right)^{2}}
$$

where $\Delta \mathrm{I} / I$, is the current instability of the objective lens, $\Delta \mathrm{E} / V$ is the energy spread of the electron gun, and $\Delta \mathrm{V} / \mathrm{V}$ is the instability in the high voltage supply. The $\mathrm{C}_{\mathrm{c}}$ envelope function describes the dampening effects caused by; $\mathrm{C}_{\mathrm{c}}$, the current and acceleration instabilities, and the energy spread of the beam, on the CTF.

$$
E_{C}(\boldsymbol{u})=e^{-\frac{1}{2} \pi^{2} \lambda^{2} \Delta_{S}^{2} u^{4}}
$$


where $\Delta_{S}$ is the defocus spread. In this work however, a Wien-type monochromator, situated directly after the electron gun, is used to limit the effect of $\mathrm{C}_{\mathrm{c}}$ by reducing the effective energy spread of the beam. ${ }^{135}$

Coma is an aberration that describes asymmetric information transfer depending on distance from the optical axis, identical point objects would appear distorted at different points from the optical axis. The term coma originates from telescope aberrations where a star would appear as a comet, cometary.

Astigmatism is caused by imperfections in electromagnetic lenses and misalignment and/or contamination of the condenser aperture, resulting in elongations of point objects in the image. Correcting coma and astigmatism is less complicated and therefore cheaper compared to $\mathrm{C}_{\mathrm{s}}$ and $\mathrm{C}_{\mathrm{c}}$, and it is also performed in conventional uncorrected TEM.

\subsection{High angle annular dark field STEM}

High angle scattering in STEM refers to angles $>3^{\circ}$ (or $>50 \mathrm{mrad}$ ) which is a range where Z-contrast is the dominating contributor to contrast in image formation, with very low contribution from phase contrast. 136,137 Z-contrast arise because a converged probe is scanned over the sample and the coherency in terms of the phase of the electron beam is lost, rendering the beam incoherent, and consequently reduces interference effects significantly. Z-contrast imaging, contrary to CTEM imaging, does not exhibit contrast reversals depending on defocus and sample thickness and is therefore intuitive in terms of interpretation.

However, in this work, quantitative STEM methods are applied to characterize the surface terminations of MXene, which requires more than an intuitive interpretation. The following paragraphs discusses the contributions to contrast and overall image intensity in HAADF STEM.

Since the STEM probe is converged the directional information of each scattered beam is spread out angularly. For that reason, an angular detector is used to collect all the scattered electrons from a virtual pixel on the sample (the point where the converged probe was placed) and the 
entire detector area is read out before the probe is rasterized to next scan position.

Moreover, thermal diffuse scattering (TDS) is increasingly probable at higher angles and give rise to intensity differences in crystallographic directions. ${ }^{137}$ To account for TDS, STEM simulations are typically employed, which is explained in the next section. Figure 3.8 presents an example of the difference contrast mechanisms in HAADF STEM and HRTEM images of a $\mathrm{Ti}_{3} \mathrm{C}_{2} \mathrm{~T}_{\mathrm{X}}$ sheet. The phase contribution is challenging to interpret when compositional variables exist, even by aid of simulations as more variables are required to be fitted, compared to Zcontrast.
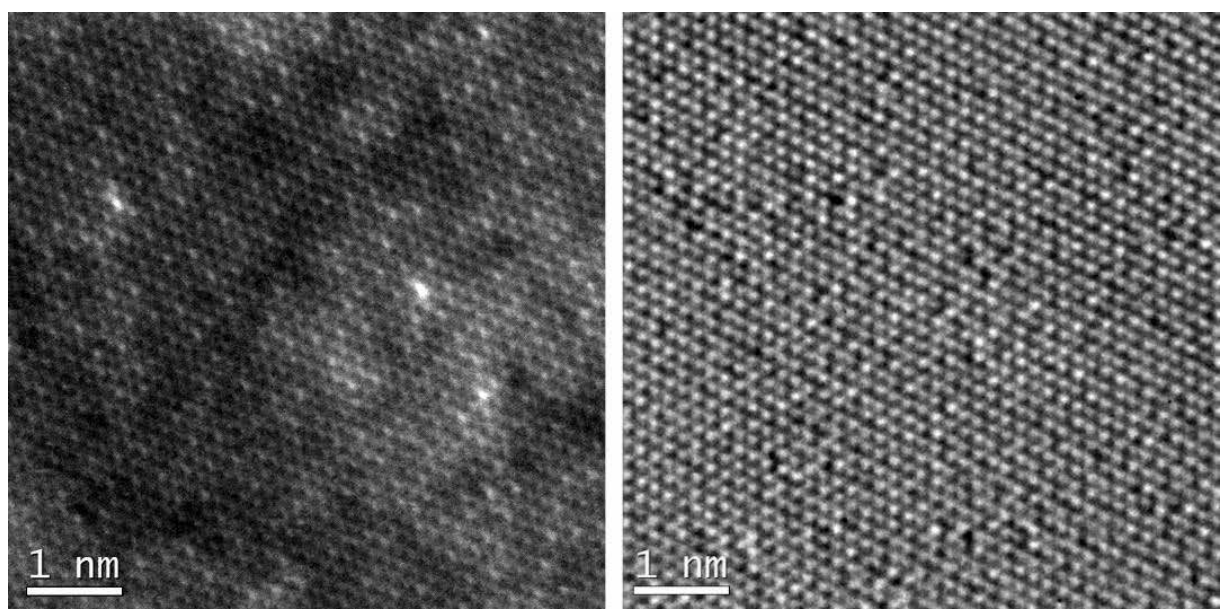

Figure 3.8. (Left) HAADF STEM image of a $\mathrm{Ti}_{3} \mathrm{C}_{2} \mathrm{~T}_{\mathrm{X}}$ sheet showing Z-contrast. (Right) HRTEM image of a $\mathrm{Ti}_{3} \mathrm{C}_{2} \mathrm{~T}_{\mathrm{X}}$ sheet showing phase contrast.

The advantage HAADF STEM image interpretation presents over HRTEM is that the atomic constituents in the projected columns can be quantified with less knowledge of the sample beforehand. However, extensive knowledge of the detector, the probe and the imaging conditions is still required for both imaging modes. Image contrast in STEM depends on the angular range of the scattered electrons collected on the detector, referred to as the collection angle, which is determined by the camera length and the geometrical limits of the microscope 
column. Furthermore, the thickness and symmetry of the sample has an effect of the probe distribution as it passes through the sample, referred to as probe channelling. ${ }^{138}$ Figure 3.9 illustrates the geometry of the probe and the scattered electron giving rise to signal in a HAADF detector at different angular ranges depending on channelling conditions and atomic element.

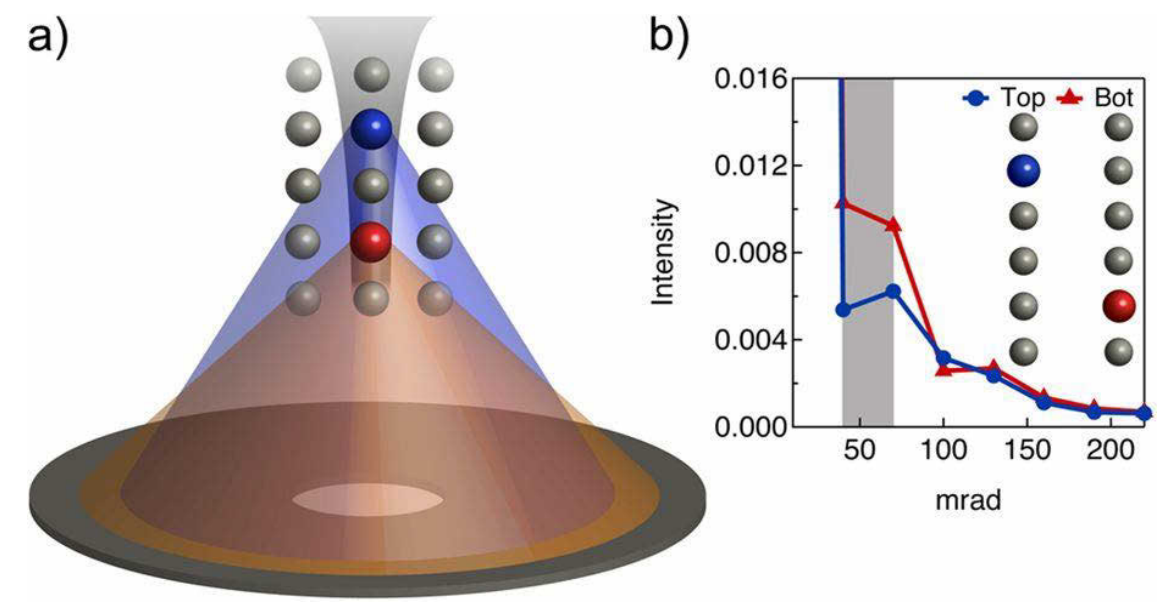

Figure 3.9. a) Illustration of scattered electrons angular range collected by an annular detector. b) Averaged intensity profile as a function of radial distance from the centre of the detector. Reused from ${ }^{139}$ under a (CC BY 4.0) license. https://creativecommons.org/licenses/by/4.0/

However, the channelling effects can be modeled by HAADF STEM simulations and aid in interpretation of experimental images. In order to conduct quantitative HAADF STEM simulations, it is required to know how the detector handles the collected electrons, referred to the detector response, which is explained in the next section. Figure 3.10. presents a simulation of the Lorentzian probe intensity depth profile passing through a $300 \AA$ thick GaAs sample in three different crosssection orientations. 

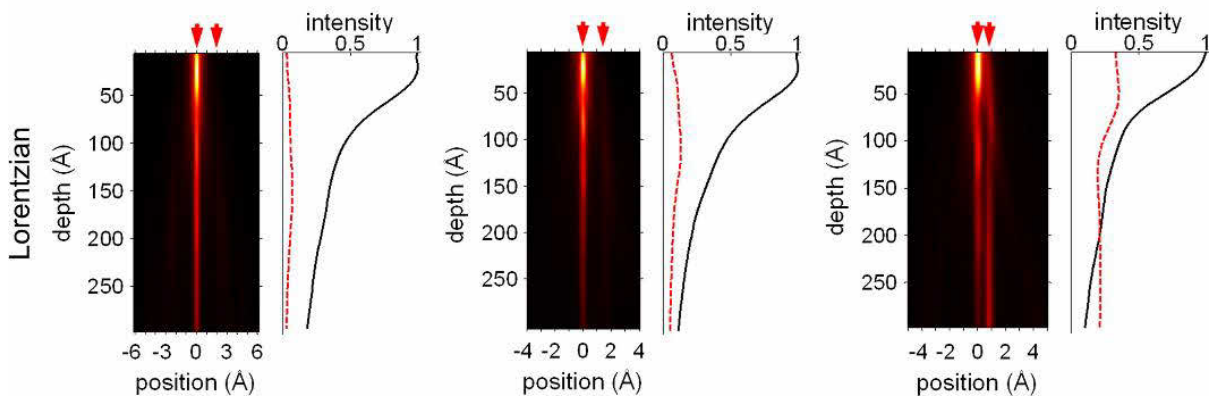

Figure 3.10. Simulated depth profiles of a Lorentzian probe propagating through a $300 \AA$ thick GaAs sample in three cross-sectional perspectives, left $<001>$, middle $<110>$, and right $<112>$. Red arrows indicate the Ga column where the probe is placed and the next nearest neighbouring As column. Adapted with permission. ${ }^{138}$ Copyright Elsevier 2014.

With probe aberrations, probe channelling and detector collection angles accounted for the remaining step before attempting quantitative data analysis is to characterize the detector.

\subsubsection{Detection system}

A typical HAADF detector consists of a scintillator, a photomultiplier, an amplifier and an A/D converter. The scintillator is used to convert electrons impacting on the detector area, into photons. The photons are then multiplied in the photomultiplier to generate a measurable electric signal. The amplifier controls the brightness and contrast settings and the signal is converted to a digital image by the A/D converter. ${ }^{140}$ In order to characterize the detector response, all the steps leading to the digital image are step-wise measured under different conditions. To ensure uniformity of the scintillator conversion over the entire detector area, the detector is scanned by the probe without a sample present, forming an image of the detector at the different camera lengths, see figure 3.11. 

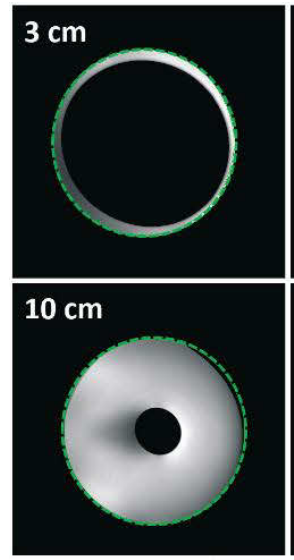

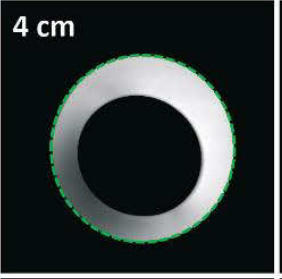

$12 \mathrm{~cm}$

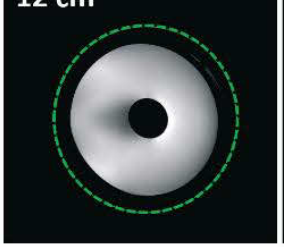

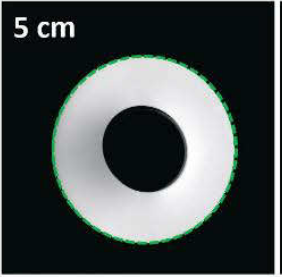

$20 \mathrm{~cm}$

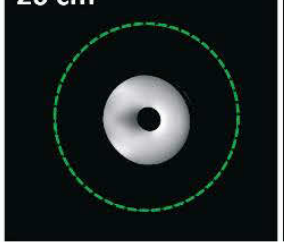

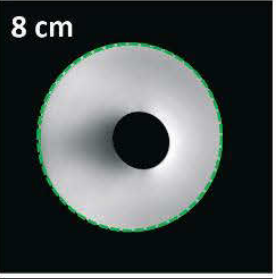

$40 \mathrm{~cm}$

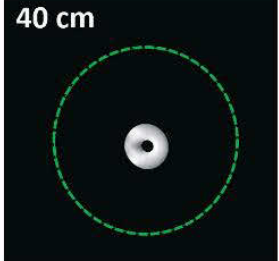

Figure 3.11. Scan images of an ADF detector at respective camera length showing the collection angles of the detector and the local variation in detector response. Reused from ${ }^{140}$ under a (CC BY 3.0) license. https://creativecommons.org/licenses/by/3.0/.

The amplifier is tested for different brightness and contrast settings on a reference sample to determine brightness and contrasts ranges with linear intensity transfer. Furthermore, the signal-to-noise ratio of the detector is estimated to rule out intensity losses caused by a low-dose probe or low dwell-times in the scan sequence. The detector response and collection angle range is then used in the STEM simulations software and intensity normalization can be performed.

\subsection{STEM image simulations}

Quantitative analysis of STEM HAADF images requires comparison with STEM simulations to interpret the effect of collection angles, probe channelling, and TDS. Which is typically neglected when interpreting STEM images intuitively by Z-contrast. There are a wide range of available softwares for STEM simulations, however in this work Dr. Probe has been used consistently. ${ }^{141}$

The principle of Dr. Probe is to perform multislice calculations and electron probe wave propagations for a predetermined crystal. ${ }^{142}$ In order to do so, a crystal model containing atomic numbers, positions, thermal 
vibration parameters, is sliced up in planes with a desired projection orientation and separation (typically corresponding to the lattice spacing of that orientation). The potential of each plane is calculated forming diffraction gratings. An electron probe is calculated using microscope specific operation parameters, aberration coefficients and convergence angle. Electron diffraction is simulated for each position of the crystal slice as the probe propagates down to each slice, and the procedure is run for the whole scan while storing the angles and the fraction of the beam that is scattered. The image is formed for a specific collection angle (angular range of the detector) Figure 3.12 illustrates an example of a $\mathrm{Ti}_{3} \mathrm{C}_{2} \mathrm{Cl}_{2}$ crystal model in a cross-section projection created using CrystalMaker ${ }^{\mathrm{TM}}$, and the corresponding simulated image using Dr. Probe.

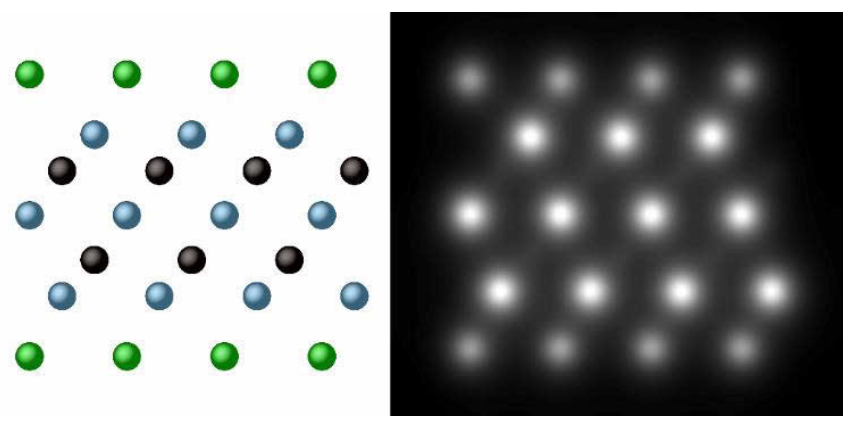

Figure 3.13. Atomic model of a $\mathrm{Ti}_{3} \mathrm{C}_{2} \mathrm{Cl}_{2}$ MXene and the corresponding HAADF STEM simulation. $(\mathrm{Ti}=$ blue, $\mathrm{C}=$ black, $\mathrm{Cl}=$ green $)$.

The calculated probe profile and experimental radial detector response is added to the image and a direct comparison of the experimental and simulated image can be performed.

\subsection{Quantitative HAADF STEM}

The purpose of quantitative HAADF STEM is to determine the elemental constituents in an atomic column in HAADF STEM images by measuring each individual column intensity and applying a modified Rutherford 
scattering formula to estimate the effective atomic number of the columns. Unfortunately, Z-contrast is not the only contributor to the HAADF STEM image intensity and to account for the contribution from the detector, probe channelling, TDS, probe profile, and probe aberrations, HAADF STEM simulations can be utilized. A comparison of experimental images with simulations can be done by identifying atomic columns in an image, averaging or integrating the intensity of the column by choosing a cell of a specific size and form. It has been suggested that averaging Voronoi cells around the atomic column centres yields results comparable to expectation, however, the average intensity was shown to depend on the size of the cell. ${ }^{138}$ It was further suggested that peak intensities give an accurate measure of the atomic column composition. However, the peak intensity was shown to be sensitive to intensity drops caused by defocus and small angle mistilts of the sample (or the electron beam). ${ }^{143}$ Integrated scattering cross-sections of different size and shapes were investigated and found robust to defocus and mistilt, ${ }^{138}$ which is the method used in paper 1 . The method was however shown to depend on sample thickness where less than 15 atomic planes thick $\mathrm{SrTiO}_{3}$ showed a low error while 75 atomic planes thick $\mathrm{SrTiO}_{3}$ showed strong variations. ${ }^{144}$ Considering the expected 5-7 atomic planes thick materials investigated in this work, the integrated scattering cross-section method was judged suitable.

\subsection{Electron energy-loss spectroscopy}

EELS in aberration corrected TEM is a powerful method for optical, electronic and elemental characterization on atomic scale. The main principle is that the inelastically scattered electrons are deflected and dispersed by a magnetic prism into an energy spectrum that is projected on a detector. The direct beam having zero energy-loss is referred to as the zero-loss peak (ZLP) even though it has a width, coming from the energy resolution of the probe (or parallel beam). The optical and vibrational energy losses $(\sim<3 \mathrm{eV})$ occur near the ZLP and can be 
detected only if a good energy resolution is achieved. Electrons with low energy losses $(\sim 50 \mathrm{eV})$ constitutes the low-loss region where energylosses from surface and bulk plasmons appear. The elemental information coming from core-shell electron excitations (s-, p-, or d-orbital electrons) to unoccupied states are found at energies $\sim>50 \mathrm{eV}$. However, the low scattering probability for inelastic scattering at high energy losses results in a $\mathrm{S} / \mathrm{N}$ ratio that limits the observable energy range up to $\sim 2.5 \mathrm{keV}$. A typical EELS spectrum is presented in figure 3.13 showing the ZLP, the low-loss region, and the core-loss region.
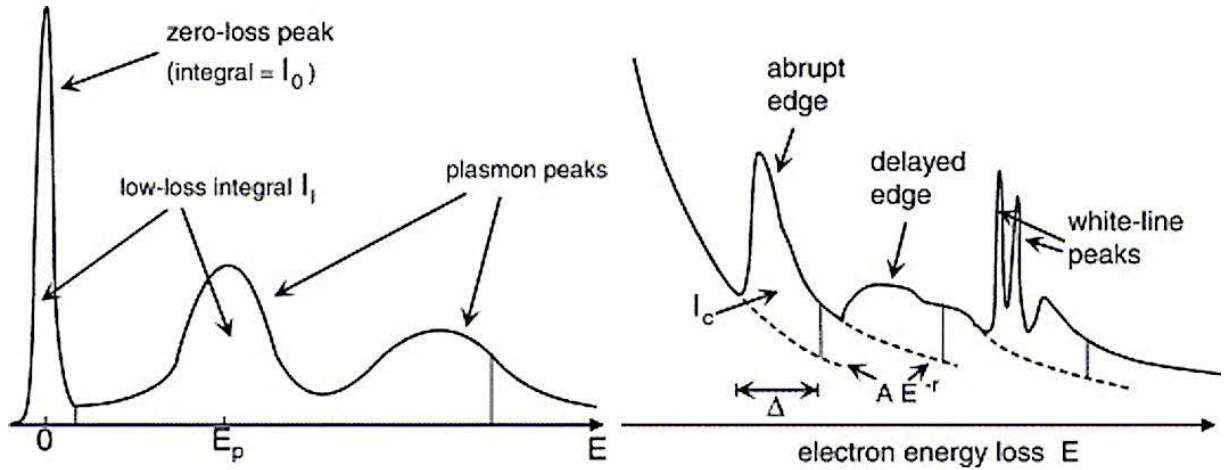

Figure 3.13. Typical EELS spectra showing the ZLP and the bulk plasmons. The core-loss region intensity is scaled up showing different edge shapes. Reused with permission. ${ }^{145}$ Copyright Elsevier 2005.

The EELS spectra can be employed to measure to relative thickness of the sample as the inelastic scattering cross-section is thickness dependent. However, in order to determine the absolute thickness, the inelastic mean free path (imfp) of the material has to be known (the probable distance travelled between inelastic scattering events). Moreover, structural and chemical transformations can be characterized using EELS as chemical shifts in the low-loss and core-loss edges occur. ${ }^{145}$ Figure 3.14 presents an example of an Fe-L edge (p-orbital) chemical shifts as a function of oxidations states of $\mathrm{Fe}$ in different compounds. 


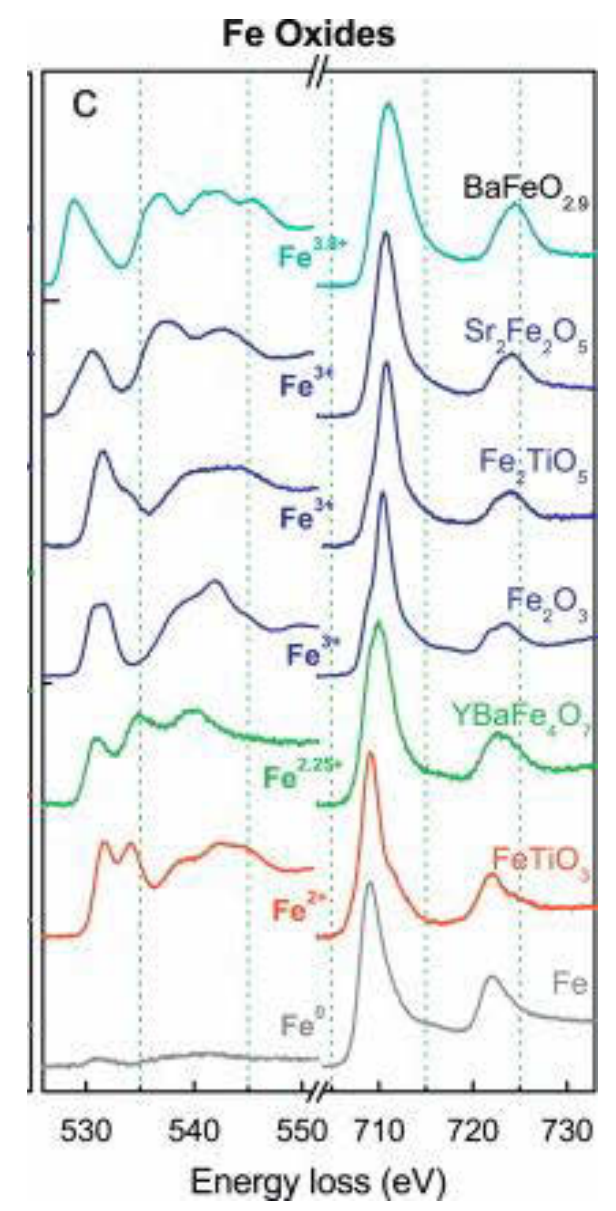

Figure 3.14. EELS core-loss spectra of O-K and Fe-L demonstrating chemical shifts caused by the oxidation states of Fe. Reused with permission. ${ }^{146}$ Copyright Elsevier 2012.

Quantitative methods exist for determining elemental concentrations, however the relative error is typically around $10 \%$ for thick samples (thickness close to $1 \mathrm{imfp}$ ). ${ }^{145}$ For very thin samples, and by using a small energy dispersion, via lowering the excitation energy of the magnetic prism, the quantification error is significantly reduced. ${ }^{145}$ Different core electrons excitations yields different edge shapes as shown in figure 3.13, and scattering cross-section models for each shape is required for a reliable quantification. In this work, EELS was employed in CTEM diffraction mode on large overview areas resulting in a parallel 
illumination of the sample and therefore a lower electron dose per unit area and thus limiting beam damage on the sensitive MXene. Although atomic resolution of elemental information is not achieved an overall composition can be estimated and most importantly, chemical shifts caused by surface reactions changing the bonding state of the core electrons can be followed.

\subsection{In situ TEM}

Stimulation of TEM samples by different physical and chemical approaches inside a TEM is a rapidly growing field, as a result of new microelectromechanical systems (MEMS) for TEM offering heating, biasing, liquid and gaseous environment stimulation of TEM samples at high stability. Stability is imperative in order to maintain atomic resolution during in situ stimulation, thereby allowing for direct observation of structural and chemical transformations on the atomic level, which is a fascinating technological achievement.

The main in situ technique employed in this work is resistive heating using a DensSolution Wildfire TEM holder with a MEMS nano heater chip. Figure 3.14 shows an example of the chip design where TEM samples can placed over a mesh allowing for electron transparency while being stimulated by heating and or electric biasing. ${ }^{147}$ 

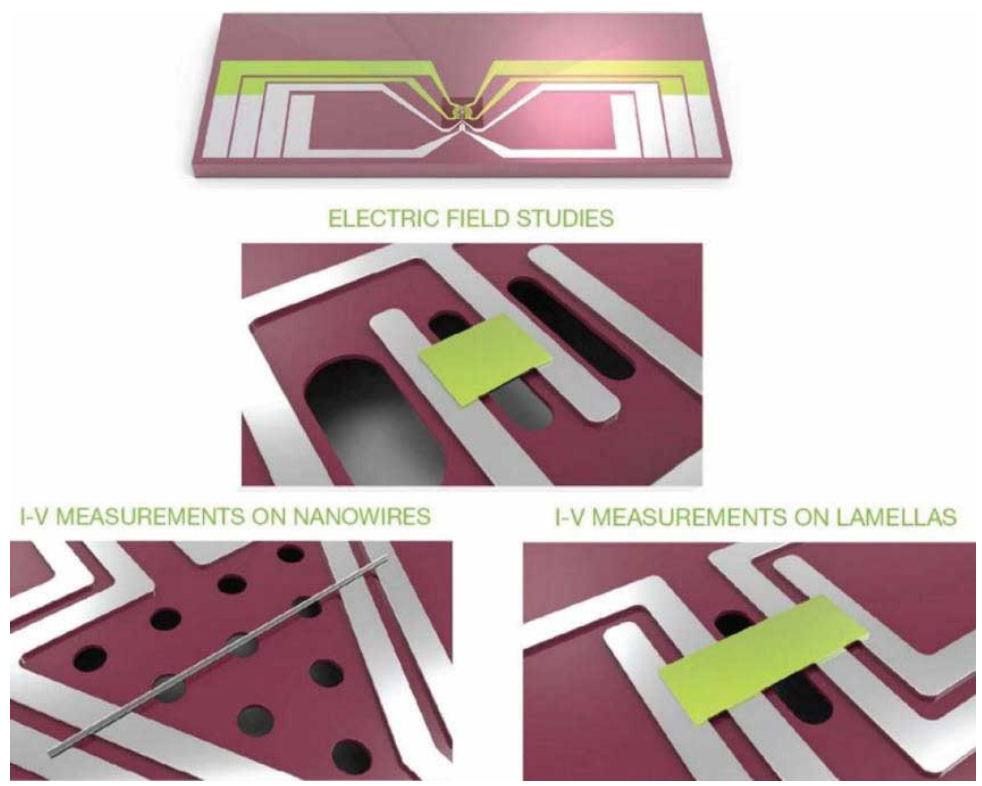

Figure 3.14. Example of a heating and biasing MEMS chip design. Reused with permission. ${ }^{147}$ Copyright Wiley-VCH Verlag GmbH \& Co. KGaA 2016.

In figure 3.15 an example of an in situ TEM investigation is presented, employing heat treatment of an InAs nanowire by using a DensSolution Wildfire heating holder. After heating up to $320^{\circ} \mathrm{C}$ the morphology of the nanowire changes, the catalyst/nanowire interface layers start to dissolve into the catalyst, and a transformation from wurtzite to zinc blende is observed at the edge of the interface. ${ }^{148}$ 


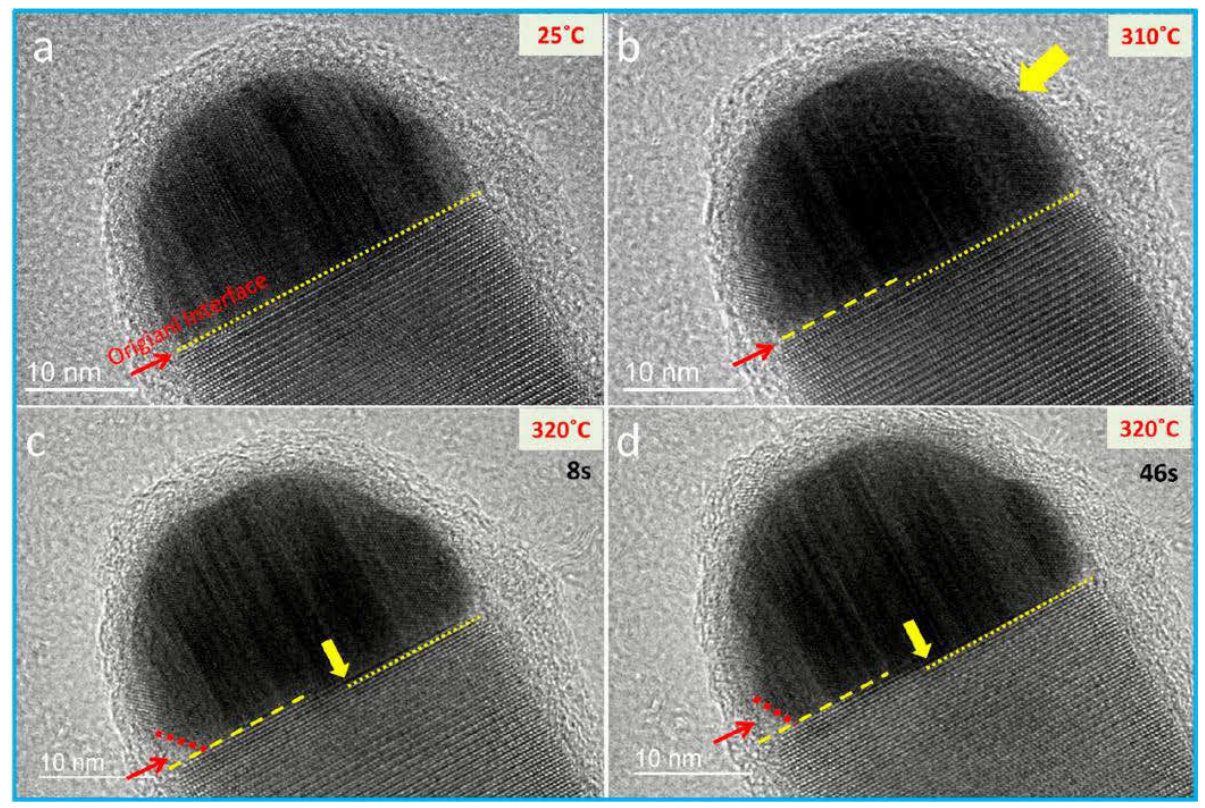

Figure 3.15. HRTEM images of an InAs nanowire covered with an Au catalyst. a)-b) show the interfacial rearrangement after heating at $25^{\circ} \mathrm{C}$ and $310^{\circ} \mathrm{C}$, respectively. c)d) show the interface after $8 \mathrm{~s}$, and $46 \mathrm{~s}$ of heating at $320^{\circ} \mathrm{C}$, respectively. Reused with permission. ${ }^{148}$ Copyright American Chemical Society 2018.

In this work, MXene samples are prepared in a diluted delaminated solution as described previously. The MXene is drop-casted on the MEMS nano chip using a microliter pipette $(0.1 \mu \mathrm{l}$ drops $)$. The result is high coverage of single flakes extending over a SiN MEMS support mesh. The nanochip can withstand operating temperature up to $1300{ }^{\circ} \mathrm{C}$ and at the same time offer a vibration free environment for atomic resolution imaging.

Heating samples inside the TEM has two advantages, 1) to follow structural and chemical transformation as a result of thermal treatment, 2) to create an environment free from contamination. The latter is especially important for 2D materials and the MXenes investigated in this work as hydrocarbon contamination always occur in a TEM at working pressures of $10^{-7}$ mbar. In addition, contamination and intercalants from the etching and delamination procedures are present on MXenes which 
renders surface characterization extremely challenging without a reliable method of removing them. In situ heating was employed to remove surface contamination on all MXenes investigated in this work. Furthermore, paper 1, 2, 3 and 4 investigate structural and chemical transformation as function of temperature inside the TEM, where papers 2 and 3 also investigated thermal treatment in gaseous environments.

\subsection{Environmental TEM}

An ETEM setup differs from a conventional TEM setup by a gas inlet system, additional differential pumping sections above and below the sample, a gas control system, a plasma cleaner, and an RGA spectrometer. ${ }^{149}$ Figure 3.16 illustrates the ETEM setup at the Center for Electron Nanoscopy, Technical University of Denmark (DTU) in Copenhagen that was employed for the investigations in papers 2 and 3.
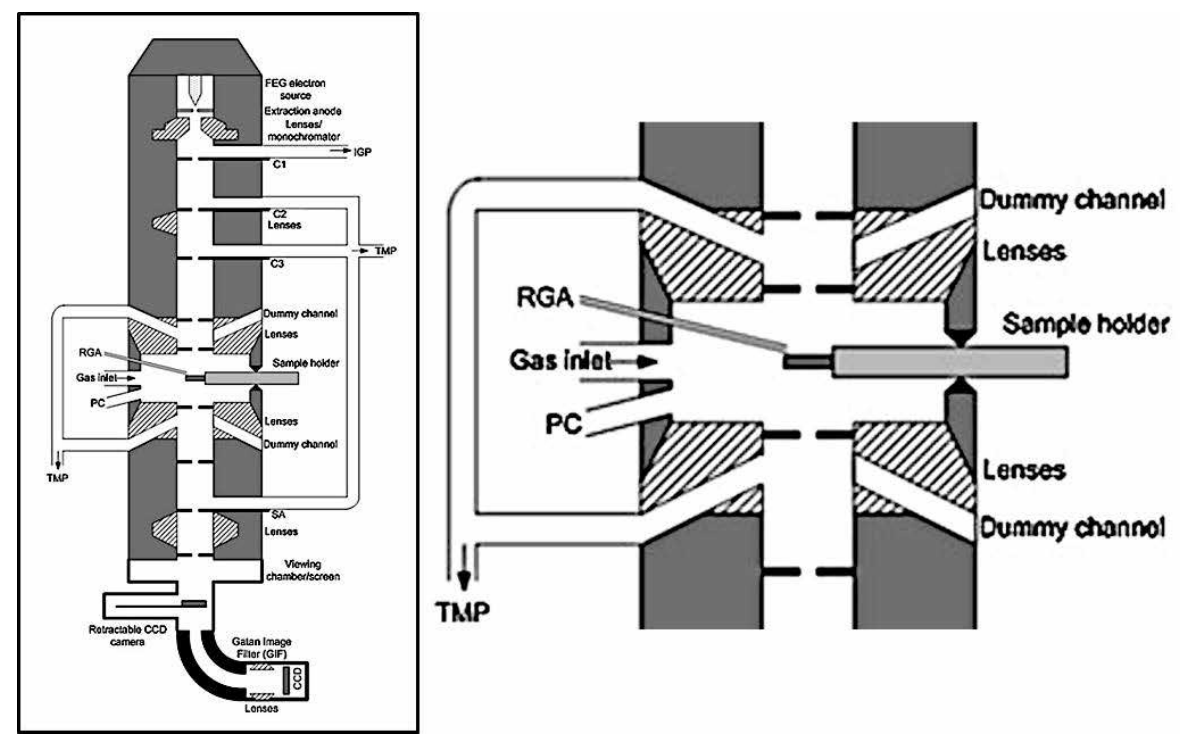

Figure 3.16. Schematic of the ETEM setup at DTU CEN consisting of a gas inlet directed toward the sample, an RGA in close proximity to the sample, differential turbopump channels, and a plasma cleaner. Adapted with permission. ${ }^{149}$ Copyright Elsevier 2012. 
This set up enables gaseous environments in a laminar flow over the sample at pressures up to $\sim 10$ mbar. Moreover, in situ heating used in conjunction to gas exposure enables chemical reactions to be investigated in operando on atomic level, which is the topic in papers 2 and 3. Lastly, RGA allows for reaction products to be detect as a function of time, pressure and temperature.

\subsection{Electron diffraction}

An ED pattern is the interference pattern obtained when an electron beam scatters on a crystal. The conditions for constructive interference are given by eq. 3.5 and illustrated in figure 3.3. In TEM the ED is used to orient the sample along high symmetry crystal orientation, called zone axis. In addition, the crystallographic information of the sample including lattice spacings and space group (or point group, or crystal system if so preferred) can be determined by measuring angles and distances between diffraction spots. ${ }^{117}$ In this work, ED was employed to monitor structural transformations of MXenes during heating in gaseous environments.

\subsection{X-ray photoelectron spectroscopy}

XPS is and technique used to characterize composition and chemistry of surface atoms. ${ }^{150}$ The principle involves an x-ray beam that illuminates a sample causing electron emission, as a result of the photoelectric effect. The electrons are collected and dispersed by a magnetic prism and thus separated into an energy spectrum. The kinetic energy of the generated electrons depends on the energy of the x-ray photon, the work function $(\Phi)$ of the material, and the binding energy of the electron prior to photoelectric emission, as shown in in eq. 3.10. ${ }^{150}$

$$
E_{B}=h v-E_{K}-\Phi,
$$

The advantage of XPS is that it is only the electrons in close proximity to the surfaces $(<10 \mathrm{~nm}$ of depths) that are allowed to reach the detector, as 
the probability of scattering increase significantly for electrons generated deeper within the sample and are therefore not contributing to the signal. 150 The electron binding energies are characteristic to each element and it is therefore possible to estimate chemical composition from an XPS spectrum. Moreover, chemical shifts caused by surface reactions is therefore possible to probe on a large scale using XPS, as the binding energies of surface electrons are altered. ${ }^{150}$ In this work, XPS was employed to estimate the composition and chemical transformation of MXene on large scale after in-situ heating in an XPS instrument, complementing the local information from TEM.

\subsection{Residual gas analysis}

RGA is a mass spectroscopy technique used to detect small fractions of molecules in a vacuum environment. ${ }^{151}$ The principle of a mass spectrometer is to measure the ratio of mass and electric charge for an element or molecular species. In order to do so, molecules are flowed through a heated filament that emits electrons that in turn ionize the molecules. A magnetic prism is used to separate the ionized molecules into an energy spectrum where the signal depends on the charge and mass of the ionized molecule. ${ }^{151}$ This is a powerful technique to measure gas composition and/or gaseous reaction products, which was employed in papers 2 and 3. 


\section{Contributions to the field}

Paper 1:

It is well-established that $2 \mathrm{D} \mathrm{Ti}_{3} \mathrm{C}_{2} \mathrm{~T}_{\mathrm{X}}$ MXene is terminated by surface groups (Tx) that dominates materials properties in, e.g. electronic and electrochemical applications. Significant differences in materials properties are predicted depending on coordination sites and the type of termination group that reside on the MXene surface $(\mathrm{O}, \mathrm{OH}$, or F). In paper 1 we report the first direct experimental evidence of manipulation of MXene surfaces by atomically resolved in situ heating in a STEM combined with STEM image simulations and by employing temperature programmed x-ray photoelectron spectroscopy (TP-XPS) from room temperature up to $750{ }^{\circ} \mathrm{C}$. In conclusion, $\mathrm{F}$ and $\mathrm{O}$ atoms are found to compete for the thermodynamically preferred fcc site, F, owing to its higher electronegativity prevails in occupying it. $\mathrm{O}$, on the other hand, are screened out from the fcc sits and are forced to reside on a bridge site or hep site. However, by increasing the temperature above $550{ }^{\circ} \mathrm{C}$ in vacuum, $\mathrm{F}$ desorption commences, and $\mathrm{O}$ relaxes to the fcc site. The $\mathrm{O} / \mathrm{F}$ contents of the surface preceding heat treatment can be varied by e.g. selecting different etchants, which in the case of a high F content opens up for a route to realize non-terminated MXenes, and by extension introducing new terminations. This is the first report on a post synthesis procedure for termination manipulation. 


\section{Paper 2:}

Previous reports on predicted adsorption properties of MXenes suggests $\mathrm{CO}_{2}$ adsorption as a promising application for MXene. On that account, in paper 2, the experiments carried out in paper 1 were reproduced, however, this time by employing an additional subsequent in situ gas exposure in the DTU CEN ETEM in Copenhagen. A method for preparing single flake TEM samples was developed in order to expose the entire $\mathrm{Ti}_{3} \mathrm{C}_{2} \mathrm{~T}_{\mathrm{X}}$ surface to $\mathrm{CO}_{2}$ gas. Aberration corrected HRTEM image-, EELS spectra-, and ED acquisition were employed to characterize the surface structure and chemical shifts of $\mathrm{C}$, $\mathrm{Ti}$, and $\mathrm{O}$ as the MXene surfaces was exposed to $\mathrm{H}_{2}$ and $\mathrm{CO}_{2}$ gas at temperatures up to $700{ }^{\circ} \mathrm{C}$. Furthermore, to ensure a spontaneous adsorption of $\mathrm{CO}_{2}$, the surfaces were required to be non-terminated. The $\mathrm{F}$ was removed by thermal treatment, as reported in paper 1, however the $\mathrm{O}$ remained. For that reason, a $\mathrm{H}_{2}$ exposure cycle at $700{ }^{\circ} \mathrm{C}$ was conducted, which resulted in depletion of O-terminations. Subsequently, $\mathrm{CO}_{2}$ gas exposure was carried out and was found to adsorb on $\mathrm{Ti}_{3} \mathrm{C}_{2} \mathrm{~T}_{\mathrm{X}}$ with remarkable adsorption efficiency. This was the first experimental evidence for $\mathrm{CO}_{2}$ adsorption on MXenes and also the first experimental report on a new termination species for MXenes, other than the inherent $\mathrm{O}, \mathrm{OH}$, or $\mathrm{F}$ coming from the synthesis steps.

\section{Paper 3:}

O-terminated MXenes were predicted highly promising for supercapacitor and HER applications, however experimental efforts in synthesizing exclusively O-terminated MXenes were lacking. For that reason, identical steps for preparing single $\mathrm{Ti}_{3} \mathrm{C}_{2} \mathrm{~T}_{\mathrm{X}}$ flakes and removal of F-terminations were performed after which $\mathrm{O}_{2}$ gas was introduced at increasing temperatures. Aberration corrected HRTEM imaging, EELS spectra, and ED acquisition were employed to characterize the surface structure and chemical shifts of $\mathrm{C}, \mathrm{Ti}$, and $\mathrm{O}$ as the MXene surfaces was exposed to $\mathrm{O}_{2}$. In conclusion, $\mathrm{O}$-saturation $\left(\mathrm{T}_{\mathrm{X}}=\mathrm{O}_{\mathrm{X}}\right.$, where $\left.X>2\right)$ was 
demonstrated experimentally for the first time, a result highly promising for supercapacitor and HER applications.

Paper 4:

Efficient $\mathrm{Cl}$ adsorption was predicted on non-terminated $\mathrm{Ti}_{2} \mathrm{C}$ MXene, however, not with $\mathrm{O}$ or $\mathrm{OH}$ terminations present, and exhibiting a high charge capacity for supercapacitor applications. In paper 4 a nontraditional MXene synthesis route was applied to realize Cl-terminated MXenes using a Lewis acid melt method. $\mathrm{Ti}_{2} \mathrm{AlC}$ and $\mathrm{Ti}_{3} \mathrm{AlC}_{2} \mathrm{MAX}$ powder was mixed with $\mathrm{ZnCl}_{2}$ and sintered at high temperature, followed by washing in aqueous $\mathrm{HCl}$. Aberration correction HAADF STEM imaging was employed in conjunction with HAADF STEM image simulation and DFT calculations in order to characterize the surface termination sites. Energy dispersive $\mathrm{x}$-ray spectroscopy (EDX) was employed to characterize the elemental composition of the MXene confirming Cl-terminations. In conclusion this was the first report on exclusive Cl-terminated MXene, which is highly significant for expanding the space of properties tuning by using Lewis acid melt synthesis methods. Furthermore, this was the first report for ordered terminations on MXene without a post synthesis thermal treatment, opening up further manipulation of materials properties.

Paper 5:

i-MAX is a new class of MAX phases first reported by researchers at Linköping University. The structure is similar to the MAX phase however it differs by chemical ordering in the plane of the surface Mlayers, where the $M$ layer consists of two different elements, $M_{1}$ and $M_{2}$. In paper 5 the $\left(\mathrm{Mo}_{2 / 3} \mathrm{Y}_{1 / 3}\right)_{2} \mathrm{AlC}$ i-MAX was selectively etched to produce i-MXene. Aberration corrected HAADF STEM imaging was employed to characterise the surface structure of single flake i-MXene TEM samples. In conclusion, this was the first experimental report on producing two different MXenes by varying the etching conditions of the 
same i-MAX phase. With a $48 \%$ concentrated HF acid etching over 12 $\mathrm{h}$, a nanoporous $\left(\mathrm{Mo}_{2 / 3} \mathrm{Y}_{1 / 3}\right)_{2} \mathrm{C}$ i-MXene was realized with a high charge capacitance. On the other hand, by using a $10 \% \mathrm{HF}$ acid for $72 \mathrm{~h}$, a significantly different structure was realized. A vacancy ordered $\mathrm{Mo}_{4 / 3} \mathrm{C}$ was formed where, in addition to the $\mathrm{Al}$ removal, the $\mathrm{Y}$ atoms were also removed by the etching, resulting in in-plane ordered vacancies at $\mathrm{Y}$ positions. The vacancy ordered sample showed a lower volumetric capacity compared to the nanoporous $\left(\mathrm{Mo}_{2 / 3} \mathrm{Y}_{1 / 3}\right)_{2} \mathrm{C}$, however the vacancy ordered structure is highly promising as a single atom catalyst supports. Altogether, it was demonstrated that selective etching of a new class of i-MAX phases may produce more than one MXene structure with varying composition which is a significant result for expanding the space of property tuning of MXenes.

\section{Paper 6:}

It is well known that MXenes react and degrade over time when exposed to moist environments. In paper 6, the effect of the environment upon $\mathrm{Nb}_{2} \mathrm{CT}_{\mathrm{X}}$ MXene as a function of time was investigated. $\mathrm{Nb}_{2} \mathrm{CT}_{\mathrm{X}}$ is consider promising for Li-ion batteries, photothermal cell ablation and hydrogen evolution. Aberration corrected HAADF STEM imaging combined with HAADF STEM image simulations were performed to characterise the surface structures of single flake $\mathrm{Nb}_{2} \mathrm{C}_{\mathrm{T}} \mathrm{X}$ MXene after exposure to ambient conditions at extended time intervals. In conclusion, it was demonstrated for the first time that $\mathrm{Nb}$ adatoms inherently reside on $\mathrm{Nb}_{2} \mathrm{C}_{\mathrm{T}} \mathrm{X}$ surfaces post etching, and that the oxidation rate is increased due to the increased reactivity of $\mathrm{Nb}$ adatoms compared to the termination species. Clustering was observed after extended exposure to ambient conditions, and finally degrading the structure after 5 days of exposure. These findings are of high importance for the design of etching procedures to increase the lifetime of MXenes. 


\section{Bibliography}

${ }^{1}$ S. Z. Butler, S. M. Hollen, L. Cao, Y. Cui, J. A. Gupta, H. R. Gutiérrez, T. F. Heinz, S. Sae Hong, J. Huang, A. F. Ismach, E. Johnston-Halperin, M. Kuno, V. V. Plashnitsa, R. D. Robinson, R. S. Ruoff, S. Salahuddin, J. Shan, L. Shi, M. G. Spencer, M. Terrones, W. Windl, and J. E. Goldberger, ACS Nano, 7, 4, 2898-2926

2 K. S. Novoselov, A. K. Geim, S. V. Morozov, D. Jiang, Y. Zhang, S. V. Dubonos, I. V. Grigorieva and A. A. Firsov, Science, 2004, 306(5696), 666-669

3 S. Wachter, D. K. Polyushkin, O. Bethge and T. Mueller, Nat. Commun., 2017, 8, 14948

${ }^{4}$ H. Wang, L. Yu, Y-H. Lee, Y. Shi, A. Hsu, M. L. Chin, L-J. Li, M. Dubey, J. Kong, and T. Palacios, Nano Lett. 2012, 12, 9, 4674-4680

5 G. E. Moore. Electronics, 1965, 38, 8,

6 Y. Sun, Q. Wu and G. Shi, Energy Environ. Sci., 2011, 4, 1113-1132

7 M. R. Lukatskaya, O. Mashtalir, C. E. Ren, Y. Dall'Agnese, P. Rozier, P. Louis Taberna, M. Naguib, P. Simon, M. W. Barsoum, Y. Gogotsi, Science, 2013, 341(6153), 1502-1505

8 D. Deng, K. S. Novoselov, Q. Fu, N. Zheng, Z. Tian and X. Bao, Nature Nanotechnology, 2016, 11, 218-230

9 S. Yang, X. Feng, X. Wang, K. Müllen, Angew. Chem. Int. Ed., 2011, 50, 5339 -5343

10 G. Liu, W. Jin and N. Xu, Angew. Chem. Int. Ed., 2016, 55,13384-13397

11 S. Borini, R. White, D. Wei, M. Astley, S. Haque, E. Spigone, N. Harris, J. Kivioja, and T. Ryhänen, ACS Nano, 2013, 7, 12, 11166-11173

12 C. Tan, X. Cao, X-J. Wu, Q. He, J. Yang, X. Zhang, J. Chen, W. Zhao, S. Han, Gwang-H. Nam, M. Sindoro, and H. Zhang, Chem. Rev. 2017, 117, 6225-6331 
13 Y. Hernandez, V. Nicolosi, M. Lotya, F. M. Blighe, Z. Sun, S. De, I. T. Mcgovern, B. Holland, M. Byrne, Y. K. Gun'ko, J. J. Boland, P. Niraj, G. Duesberg, S. Krishnamurthy, R. Goodhue, J. Hutchison, V. Scardaci, A. C. Ferrari and J. N. Coleman, Nature Nanotechnology, 2008, 3, 563-568

14 J. N. Coleman, M. Lotya, A. O’Neill, S. D. Bergin, P. J. King, U. Khan, K. Young, A. Gaucher, S. De, R. J. Smith, I.V. Shvets, S. K. Arora, G. Stanton, H-Y. Kim, K. Lee, G. T. Kim, G. S. Duesberg, T. Hallam, J. J. Boland, J. J. Wang, J. F. Donegan, J. C. Grunlan, G. Moriarty, A. Shmeliov, R. J. Nicholls, J. M. Perkins, E. M. Grieveson, K. Theuwissen, D. W. McComb, P. D. Nellist, V. Nicolosi, Science, $2011,331(6017), 568-571$

15 A. K. Geim and I. V. Grigorieva, Nature, 2013, 499, 419-425

16 D. Jariwala, V. K. Sangwan, L.n J. Lauhon, T. J. Marks, and M. C. Hersam, ACS Nano, 2014, 8, 2, 1102-1120

17 S. Lei, X. Wang, B. Li, J. Kang, Y. He, A. George, L. Ge, Y. Gong, P. Dong, Z. Jin, G. Brunetto, W. Chen, Z-T. Lin, R. Baines, D. S. Galvão, J. Lou, E. Barrera, K. Banerjee, R. Vajtai and P. Ajayan

, Nature Nanotechnology, 2016, 11, 465-471

18 X. Chen and A. R. McDonald, Adv. Mater., 2016, 28, 5738-5746

19 M. W. Barsoum, Prog. Solid St. Chem., 2000, 28, 201-281.

20 M. Naguib, M. Kurtoglu, V. Presser, J. Lu, J. Niu, M. Heon, L. Hultman, Y. Gogotsi, M. W. Barsoum, Adv. Mater., 2011, 23, 4248.

21 M. A. Hope, A. C. Forse, K. J. Griffith, M. R. Lukatskaya, M. Ghidiu, Y. Gogotsi and C. P. Grey, Phys. Chem. Chem. Phys., 2016, 18, 5099

22 Nuala M. Caffrey, Nanoscale, 2018, 10, 13520-13530

23 M. Naguib, J. Come' B. Dyatkin, V. Presser, P-L. Taberna, P. Simon' M. W. Barsoum, Y. Gogotsi, Electroch. Commun., 2012,

$16(1), 61-64$ 
24 L. Ding, Y. Wei, L. Li, T. Zhang, H. Wang, J. Xue, L-X. Ding, S. Wang, J. Caro and Y. Gogotsi, Nat. Commun., 2018, 9, 155

25 J. Liu, H-B. Zhang, R. Sun, Y. Liu, Z. Liu, A. Zhou, and Z-Z. Yu, Adv. Mater., 2017, 29,1702367

26 A. Morales-Garcia, A. Fernandez-Fernandez, F. Vines and F. Illas, J. Mater. Chem. $A, 2018,6,3381$

27 N. Li, X. Chen, W.-J. Ong, D. R. MacFarlane, X. Zhao, A. K. Cheetham, and C. Sun, ACS Nano, 2017, 11, 10825-10833

28 J. Pang, R.1 G. Mendes, A. Bachmatiuk, L. Zhao, H. Q. Ta, T. Gemming, H. Liu, Z. Liu and M. H. Rummeli, Chem. Soc. Rev., 2019, 48, 72-133

29 Y. Xie, M. Naguib, V. N. Mochalin, M. W. Barsoum, Y. Gogotsi, X. Yu, K-W. Nam, X-Q. Yang, A. I. Kolesnikov, and P. R. C. Kent, J. Am. Chem. Soc., 2014, 136, 6385-6394

30 Y. Xie, Y. Dall'Agnese, M. Naguib, Y. Gogotsi, M.1 W. Barsoum, H. L. Zhuang, and P. R. C. Kent, ACS Nano, 2014, 8(9), 9606-9615

31 R.B. Rakhi, B. Ahmed, M.N. Hedhili, D.H. Anjum, H.N. Alshareef, Chem. Mater., 2015, 27, 5314-5323.

32 J. Li, X.T. Yuan, C. Lin, Y.Q. Yang, L. Xu, X. Du, J.L. Xie, J.H. Lin, J.L. Sun, $A d v$. Energy Mater., 2017, 7, 1602725.

33 Z. Wei Seh, K. D. Fredrickson, B. Anasori, J. Kibsgaard, A. L. Strickler, M. R. Lukatskaya, Y. Gogotsi, T. F. Jaramillo, and A. Vojvodic, ACS Energy Lett., 2016, $1,589-594$

34 A. D. Handoko, K. D. Fredrickson, B. Anasori, K. W. Convey, L. R. Johnson, Y. Gogotsi, A. Vojvodic, and Z. Wei Seh, ACS Appl. Energy Mater., 2018, 1, $173-180$

35 X. Yu, X. Cai, H. Cui, S-W. Lee, X-F. Yu and B. Liu, Nanoscale, 2017, 9, 17859 
36 T. Li, L. Yao, Q.Liu, J. Gu, R. Luo, J. Li, X.Yan, W. Wang, P. Liu, B. Chen, W. Zhang, W. Abbas, R. Naz, D. Zhang, Angew. Chem., 2018, 130, 6223-6227

37 Q. Tao, M. Dahlqvist, J. Lu, S. Kota, R. Meshkian, J. Halim, J. Palisaitis, L. Hultman, M. W. Barsoum, P. O. Å. Persson \& J. Rosen, Nat. Comm., 2017, 8, 14949

38 C. J. Zhang, S. Pinilla, N. McEvoy, C.P. Cullen, B. Anasori, E. Long, S-H. Park, A. Seral-Ascaso, A. Shmeliov, D. Krishnan, C. Morant, X. Liu, G. S. Duesberg, Y. Gogotsi, and V. Nicolosi, Chem. Mater., 2017, 29, 4848-4856

39 T. Habib, X. Zhao, S. A. Shah, Y. Chen, W. Sun, H. An, J. L. Lutkenhaus, M. Radovic and M. J. Green, npj 2D Mat. and Appl., 2019, 3, 8

40 M. Naguib, J. Halim, J. Lu, Kevin M. Cook, L. Hultman, Y. Gogotsi, and M. W. Barsoum, J. Am. Chem. Soc., 2013, 135, 15966-15969

41 H. Lin, S. Gao, C. Dai, Y. Chen, and J. Shi, J. Am. Chem. Soc., 2017, 139, 45, 1623516247

42 X. Li, X. Wang, L. Zhang, S. Lee, H. Dai, Science, 2008, 319(5867), 1229-1232

43 F. Schwierz, Nat. Nanotec., 2010, 5, 487-496

44 Y. Wang, Z. Shi, Y. Huang, Y. Ma, C. Wang, M. Chen, and Y. Chen, J. Phys. Chem. C, 2009, 113, 13103

45 Y. Sun, Q. Wu and G. Shi, Energy Environ. Sci., 2011, 4, 1113-1132

46 C. I.L. Justino, A. R. Gomes, A. C. Freitas, A. C. Duarte, T. A.P. Rocha-Santos, Trends in Analytical Chemistry,2017, 91, 53

47 A. Nag, A. Mitra, S. Chandra Mukhopadhyay, Sensors And Actuators A, 2018, 270, 177177

48 G. Tai, T. Hu, Y. Zhou, X. Wang, J. Kong, T. Zeng, Y. You, and Q. Wang, Angew. Chem. Int. Ed., 2015, 54, 15473-15477

49 L. Tao, E. Cinquanta, D. Chiappe, C. Grazianetti, M. Fanciulli, M. Dubey, A. Molle, and D. Akinwande, Nat. Nanotec., 2015, 10, 227-231

50 M. E. Dávila, L. Xian, S. Cahangirov, A. Rubio and G. Le Lay, New J. Phys., 2014, 16095002 
51 H. Liu, A. T. Neal, Z. Zhu, Z. Luo, X. Xu, D. Tománek, and P. D. Ye, ACS Nano, 2014, 8 (4), 4033-4041

52 C. R. Ryder, J. D. Wood, S. A. Wells, Y. Yang, D. Jariwala, T. J. Marks, G. C. Schatz and M. C. Hersam, Nat. Chem., 2016, 8, 597-602

53 F-f. Zhu, W-j. Chen, Y. Xu, C-l. Gao, D-d. Guan, C-h. Liu, D. Qian, S-C. Zhang and J-f. Jia, Nat. Mat., 2015, 14, 1020-1025

54 K. F. Mak, C. Lee, J. Hone, J. Shan, and T. F. Heinz, Phys. Rev. L., 2010, 105, 136805

55 A. Gomathi, A. K. Manna, D. J. Late, R. Datta, S. K. Pati, and C. N. R. Rao, Angew. Chem. Int. Ed., 2010, 49, 4059-4062

56 D. Pacilé, J. C. Meyer, C. O. Girit and A. Zettl , Appl. Phys. Lett., 2008, 92, 133107

57 L. Ci, L. Song, C. Jin, D. Jariwala, D. Wu, Y. Li, A. Srivastava, Z. F. Wang, K. Storr, L. Balicas, Feng Liu, and P.1 M. Ajayan, Nature Materials, 2010, 9, 430-435

58 A. Thomas, A. Fischer, F. Goettmann, M. Antonietti, J. O. Muller, R. Schlogl and J. M. Carlsson, J. Mater. Chem., 2008, 18, 4893

59 Z. Y. Al Balushi, K. Wang, R. K. Ghosh, R. A. Vila, S. M. Eichfeld, J. D. Caldwell, X. Qin, Y.-C. Lin, P. A. DeSario, G. Stone, S. Subramanian, D. F. Paul, R. M. Wallace, S. Datta, J. M. Redwing, J. A. Robinson, Nat. Mater., 2016, 15, 1166

60 J. Mei, T. Liao, L. Kou, and Z. Sun, Adv. Mater., 2017, 29, 1700176

61 L. Peng, P. Xiong, L. Ma, Y. Yuan, Y. Zhu, D. Chen, X. Luo, J. Lu, K. Amine, and G. Yu, Nat. Commun., 2017, 8, 15139

62 A. K. Geim \& I. V. Grigorieva, Nature, 2013, 499, 419-425

63 N. Mounet, M. Gibertini, P. Schwaller, D. Campi, A. Merkys, A. Marrazzo, T. Sohier, I. Eligio Castelli, A. Cepellotti, G. Pizzi and N. Marzari, Nat. Nanotec., $2018,13,246-252$

64 M. Sokol, V. Natu, S. Kota, and M. W. Barsoum, Trends in Chemistry, Month Year, Vol. xx, No. yy, In print 
65 M. Nechiche, T. Cabioc'h, E. N. Caspi, O. Rivin, A. Hoser, V. Gauthier-Brunet, P. Chartier, and S. Dubois, Inorg. Chem., 2017, 56, 23, 14388-14395

66 C.-C. Lai, H. Fashandi, J. Lu, J. Palisaitis, P. O. Å. Persson, L. Hultman, P. Eklund and J. Rosen, Nanoscale, 2017, 9, 17681-17687

67 Z. Liu, E. Wu, J. Wang, Y. Qian, H. Xiang, X. Li, Q. Jin, G. Sun, X. Chen, J. Wang, M. Li, Acta Mater., 2014, 73, 186-193

68 J. Halim, M. R. Lukatskaya, K. M. Cook, J. Lu, C. R. Smith, L.-Å. Naslund, S. J. May, L. Hultman,§Y. Gogotsi, P. Eklund,and M. W. Barsoum, Chem. Mater., 2014, 26, 2374-2381

69 B. Anasori, M. R. Lukatskaya, Y. Gogotsi, Nature Reviews Materials, 2017, 2, 16098

70 Donald M. Mattox, in Handbook of Physical Vapor Deposition (PVD) Processing (Second Edition), 2010

71 V. Mauchamp, M. Bugnet, E. P. Bellido, G. A. Botton, P. Moreau, D. Magne, M. Naguib, T. Cabioc'h, and M. W. Barsoum, Phys. Rev. B, 2014, 89, 235428

72 O. Mashtalir, M. Naguib, V. N. Mochalin, Y. Dall'Agnese, M. Heon, M. W. Barsoum \& Y. Gogotsi, Nat. Commun., 2013, 4, 1716

73 O. Mashtalir, K. M. Cook, V. N. Mochalin, M. Crowe, M. W. Barsoum and Y. Gogotsi, J. Mater. Chem. A, 2014, 2, 14334

74 A. Lipatov, M. Alhabeb, M. R. Lukatskaya, A. Boson, Y. Gogotsi and A. Sinitskii, $A d v$. Electron. Mater., 2016, 2, 1600255

75 T.Habib, X. Zhao, S. A. Shah, Y. Chen, W. Sun, H. An, J. L. Lutkenhaus, M. Radovic and M. J. Green, npj 2D Materials and Applications, 2019, 3, 8

76 Y. Chae, S. Joon Kim, S.-Y. Cho, J. Choi, K. Maleski, B.-J. Lee, H.-T. Jung, Y. Gogotsi,b Y. Lee and C. Won Ahn, Nanoscale Advance, 2019

77 M. Winter and R. J. Brodd, What are batteries, fuel cells, and supercapacitors?, Chem. Rev., 2004, 104, 4245-4269 
78 Y. Xie, M. Naguib, V. N. Mochalin, M. W. Barsoum, Y. Gogotsi, X. Yu, K.-W. Nam, X.-Q. Yang, A. I. Kolesnikov, and P. R. C. Kent, J. Am. Chem. Soc., 2014, 136(17), 6385-6394

79 X. Liang, A. Garsuch, L. F. Nazar, Angew. Chem. Int. Ed., 2015, 54: 3907-3911.

80 Q. Pang, X. Liang, C. Kwok, L. F. Nazar, J. Electrochem. Soc., 2015, 162, A2567

81 X. Wang, S. Kajiyama, H. Iinuma, E. Hosono, S. Oro, I. Moriguchi, M. Okubo, and A. Yamada, Nat. Commun., 2015, 6, 6544

82 Yu Xie, Yohan Dall'Agnese, Michael Naguib, Yury Gogotsi, Michel W. Barsoum, Houlong L. Zhuang, and Paul R. C. Kent

ACS Nano, 2014, 8 (9), 9606-9615

83 M. R. Lukatskaya, O. Mashtalir, C. E. Ren, Y. Dall'Agnese, P. Rozier, P. L. Taberna, M. Naguib, P.Simon, M. W. Barsoum, Y. Gogotsi, Science, 2013, 341(6153), 1502-1505

84 M. Ghidiu, M. R. Lukatskaya, M. Q. Zhao, Y. Gogotsi and M. W. Barsoum, Nature, $2014,516,78$.

85 Y. Tao, X. Xie, W. Lv, D.-M. Tang, D. Kong, Z. Huang, H. Nishihara, T. Ishii, B. Li, D. Golberg, F. Kang, T. Kyotani \& Q.-H. Yang, Sci. Rep., 2013, 3, 2975

86 Z. Fan, Y. Wang, Z. Xie, D. Wang, Y. Yuan, H. Kang, B. Su, Z. Cheng, and Y. Liu., Adv. Sci. (Weinh)., 2018, 5(10), 1800750

87 J. Wang, J. Tang, B. Ding, V. Malgras, Z. Chang, X. Hao, Y. Wang, H. Dou, X. Zhang \& Y. Yamauchi, Nat. Commun., 2017, 8, 15717

88 X. Wang, X. Shen, Y. Gao, Z. Wang, R. Yu, L. Chen, J. Am. Chem. Soc.2015, 137, 2715 
89 C. Si, J. Zhou, Z. Sun, ACS Appl. Mater. Interfaces 2015, 7, 17510.

90 M. Khazaei, M. Arai, T. Sasaki, A. Ranjbar, Y. Liang, S. Yunoki, Phys. Rev. B 2015, $92,075411$.

91 M. Khazaei, A. Ranjbar, M. Arai, S. Yunoki, Phys. Rev. B 2016, 94, 125152.

92 Y. Liang, M. Khazaei, A. Ranjbar, M. Arai, S. Yunoki, Y. Kawazoe, H. Weng, Z. Fang, Phys. Rev. B 2017, 96, 195414.

93 C. Si, K. H. Jin, J. Zhou, Z. Sun, F. Liu, Nano Lett. 2016, 16, 6584.

94 H. Fashandi, V. Ivády, P. Eklund, A. L. Spetz, M. I. Katsnelson, I. A. Abrikosov, Phys. Rev. B 2015, 92, 155142.

95 Y. Xie, P. R. C. Kent, Phys. Rev. B 2013, 87, 235441

96 K. Hantanasirisakul, Prof. Y. Gogotsi, Adv. Mater., 2018, 30, 1804779

97 M. Khazaei, M. Arai, T. Sasaki, C.-Y. Chung, N. S. Venkataramanan, M. Estili, Y. Sakka, Y. Kawazoe, Adv. Funct. Mater.2013, 23, 2185

98 C. Si, J. Zhou, Z. Sun, ACS Appl. Mater. Interfaces 2015, 7, 17510.

99 B. Anasori, C. Shi, E. J. Moon, Y. Xie, C. A. Voigt, P. R. C. Kent, S. J. May, S. J. L. Billinge, M. W. Barsoum, Y. Gogotsi, Nanoscale Horiz. 2016, 1, 227

100 L. Dong, H. Kumar, B. Anasori, Y. Gogotsi, V. B. Shenoy, J. Phys. Chem. Lett.2017, 8, 422.

101 J. Yang, X. Zhou, X. Luo, S. Zhang, L. Chen, Appl. Phys. Lett. 2016, 109, 203109.

102 X. H. Zha, J. Zhou, K. Luo, J. Lang, Q. Huang, X. Zhou, J. S. Francisco, J. He, S. Du, J. Phys.: Condens. Matter 2017, 29, 165701.

103 F. Shahzad, M. Alhabeb, C. B. Hatter, B. Anasori, S. Man Hong, C. M. Koo, Y. Gogotsi, Science, 2016, 353(6304), 1137-1140

104 S. J. Kim, H.-J. Koh, C. E. Ren, O. Kwon, K. Maleski, S.-Y. Cho, B. Anasori, C.K. Kim, Y.-K. Choi, J. Kim, Y. Gogotsi, and H.-T. Jung, ACS Nano, 2018, 12 (2), 986-993 
105 Z. Ling, C. E. Ren, M.-Q. Zhao, J. Yang, J. M. Giammarco, J. Qiu, M. W. Barsoum, and Yury Gogotsi, Proc. Natl. Acad. Sci. 2014, 111(47), 16676-16681.

106 M. Naguib, O. Mashtalir, J. Carle, V. Presser, J. Lu, L. Hultman, Y. Gogotsi, M. W. Barsoum, ACS Nano 2012, 6, 1322.

107 C. J. Zhang, B. Anasori, A. Seral-Ascaso, S. H. Park, N. McEvoy, A. Shmeliov, G. S. Duesberg, J. N. Coleman, Y. Gogotsi, V. Nicolosi, Adv. Mater. $2017,29,1702678$.

108 E. S. Muckley, M. Naguib and I. N. Ivanov, Nanoscale, 2018, 10, 21689

109 D. Wang, Y. Gao, Y. Liu, Y. Gogotsi, X. Meng, G. Chen and Y. Wei, J. Mater. Chem. A, 2017, 5, 24720-24727

110 J. Halim, K. M. Cook, M. Naguib, P. Eklund, Y. Gogotsi, J. Rosen, M. W. Barsoum, Appl. Surf. Sci., 2016 362, 406-417.

111 K. J. MacKenzie and M. E. Smith, Multinuclear Solid-State Nuclear Magnetic Resonance of Inorganic Materials , 2002

112 G. Li, L. Tan, Y. Zhang, B. Wu, and L. Li, Langmuir, 2017, 33, 9000-9006

113 R. B. Rakhi, Bilal Ahmed, M. N. Hedhili, Dalaver H. Anjum, and H. N. Alshareef, Chem. Mater. 2015, 27, 5314-5323

114 J. L. Hart, K. Hantanasirisakul, A. C. Lang, B. Anasori, D. Pinto, Y. Pivak, J. Tijn van Omme, S. J. May, Y. Gogotsi \& M. L. Taheri, Nat. Commun., 2019, 10, 522

115 Y. Yoon, T. Anh Le, A. P. Tiwari, I. Kim, M. W. Barsoum and H. Lee, Nanoscale, $2018,10,22429$

117 Williams, D. B. \& Carter, C. B. Transmission electron microscopy: A textbook for materials science (Springer Science+Business Media, LLC, 2009, ISBN: 978-0387-76502-0), second edn.

118 G. Binnig, F. F. Quate, C. Gerber, Phy. Rev. Lett., 1986, 56 (9), 930-933

119 G. Binnig, H. Rohrer, Ch. Gerber, and E. Weibel, Phys. Rev. Lett., 1982, 49, 57 61 
120 M. Knoll and E. Ruska, Z. Phys., 1932, 78, 318-339

121 Lord Rayleigh, Wave theory of light, in: Scientific Papers by John William Strutt, Baron Rayleigh, vol. 3, Cambridge University Press, Cambridge, 1902, 47-189

122 O. Scherzer, J. Appl. Phys., 1949, 20, 20-28

123 B.J. Inkson, Materials Characterization Using Nondestructive Evaluation (NDE) Methods., Elsevier, 2016.

124 E. Rutherford, Philosophical Magazine Series 6, 1911, 21: 125, $669-688$

125 R.F. Egerton, Ultramicroscopy 127 (2013) 100-108

126 Ryan J. Wu, Anudha Mittal, Michael L. Odlyzko, and K. Andre Mkhoyan, Microsc. Microanal. 23, 794-808, 2017

127 S.J. Haigh, B. Jiang, D. Alloyeau, C. Kisielowski, A.I. Kirkland, Ultramicroscopy, $2013,133,26-34$

128 S. J. Pennycook, M. Varela, M. F. Chisholm, A. Y. Borisevich, A. R. L. Ar, K. v. Benthem, M. P. Oxley, W. Luo, J. R. McBride, S. J. Rosenthal, S. H. Oh, D. L. Sales, S. I. Molina, K. Sohlberg and S. T. Pantelides, in: The Oxford Handbook of Nanoscience and Nanotechnology, ed. A. V. Narlikar and Y. Y. Fu, Oxford University Press, Oxford, United Kingdom, 2010, p. 205

129 S. I. Sanchez, M. W. Small, S. Sivaramakrishnan, J.-G. Wen, J.-M. Zuo and R. G. Nuzzo, Anal. Chem., 2010, 82, 2599-2607

130 H. H. Rose, Sci. Technol. Adv. Mater. 9, 2008, 014107

131 H. H. Rose, J. Electron Microsc., 2009, 58, 77-85

132 P. E. Batson, N. Dellby and O. L. Krivanek, Nature, 2002, 418, 617-620

133 F. Hosokawa, H. Sawada, Y. Kondo, K. Takayanagi and K. Suenaga, Microscopy, 2013, 62(1): 23-41

134 C.-N. Hsiao, S.-Y. Kuo, F.-I Lai and W.-C. Chen, Nanoscale Research Letters, 9 (578), 1-7 
135 P. Tiemeijer, M.Bischoff, B.Freitag \& C.Kisielowski, Ultramicroscopy, 2012, 114, $72-81$

136 A.V. Crewe, J. Wall, J.P. Langmore, Science, 1970, 168, 1338

137 S.J. Pennycook and D.E. Jesson, Ultramicroscopy, 1991, 37, 14

138 D.T. Nguyen, S.D. Findlay, J. Etheridge, Ultramicroscopy, 2014, 146, 6-16

139 J. Y. Zhang, J. Hwang, B. J. Isaac \& S. Stemmer, Scientific Reports, 2015, 5, 12419

140 L. Jones, IOP Conference Series: Materials Science and Engineering, 2016, 109 012008 .

141 J. Barthel, Ultramicroscopy, 2018, 193, 1-11

142 J.M. Cowley, A.F. Moodie, Acta Crystallographica, 1957, 10 609-619.

143 H. E, K.E. MacArthur, T.J. Pennycook, E. Okunishi, A.J. D'Alfonso, N.R. Lugg, L.J. Allen, P.D. Nellist, Ultramicroscopy,2013, 133, 109-119

144 A. De Backer, A De wael, J. Gonnissen and S. Van Aert, Ultramicroscopy, 2015, $151,46-55$

145 R. F. Egerton and M. Malac , J. Electron Spectrosc. Relat. Phenom., 2005, 143 , 43 -50

146 H. Tan, J. Verbeeck, A. Abakumov, G. Van Tendeloo, Ultramicroscopy, 2012, 116, 24-33

147 H. H. Pérez Garza, K. Zuo, Y. Pivak, D. Morsink, M. Zakhozheva, M. Pen, S. van Weperen, Q. Xu, European Microscopy Congress 2016: Proceedings

148 Z. Zhang, N. Liu, L. Li, J. Su, P.-P. Chen, W. Lu, Y. Gao, and J. Zou, Nano Lett. 2018, 18, 6597-6603

149 J. B. Wagner, F. Cavalca, C. D. Damsgaard, L. D.L. Duchstein, T. W. Hansen, Micron, 2012, 43, 1169-1175

150 P. Van der Heide, X-ray photoelectron spectroscopy: an introduction to principles and practices; John Wiley \& Sons, 2011

151 J. O'Hanlon, A user's guide to vacuum technology. 3rd ed. Hoboken NJ: WileyInterscience 2003 


\section{Papers}

The papers associated with this thesis have been removed for copyright reasons. For more details about these see:

http://urn.kb.se/resolve?urn=urn:nbn:se:liu:diva-156935 


\section{FACULTY OF SCIENCE AND ENGINEERING}

Linköping Studies in Science and Technology, Dissertation No. 1986, 2019 Department of Physics, Chemistry and Biology (IFM)

Linköping University

SE-581 83 Linköping, Sweden

www.liu.se 